
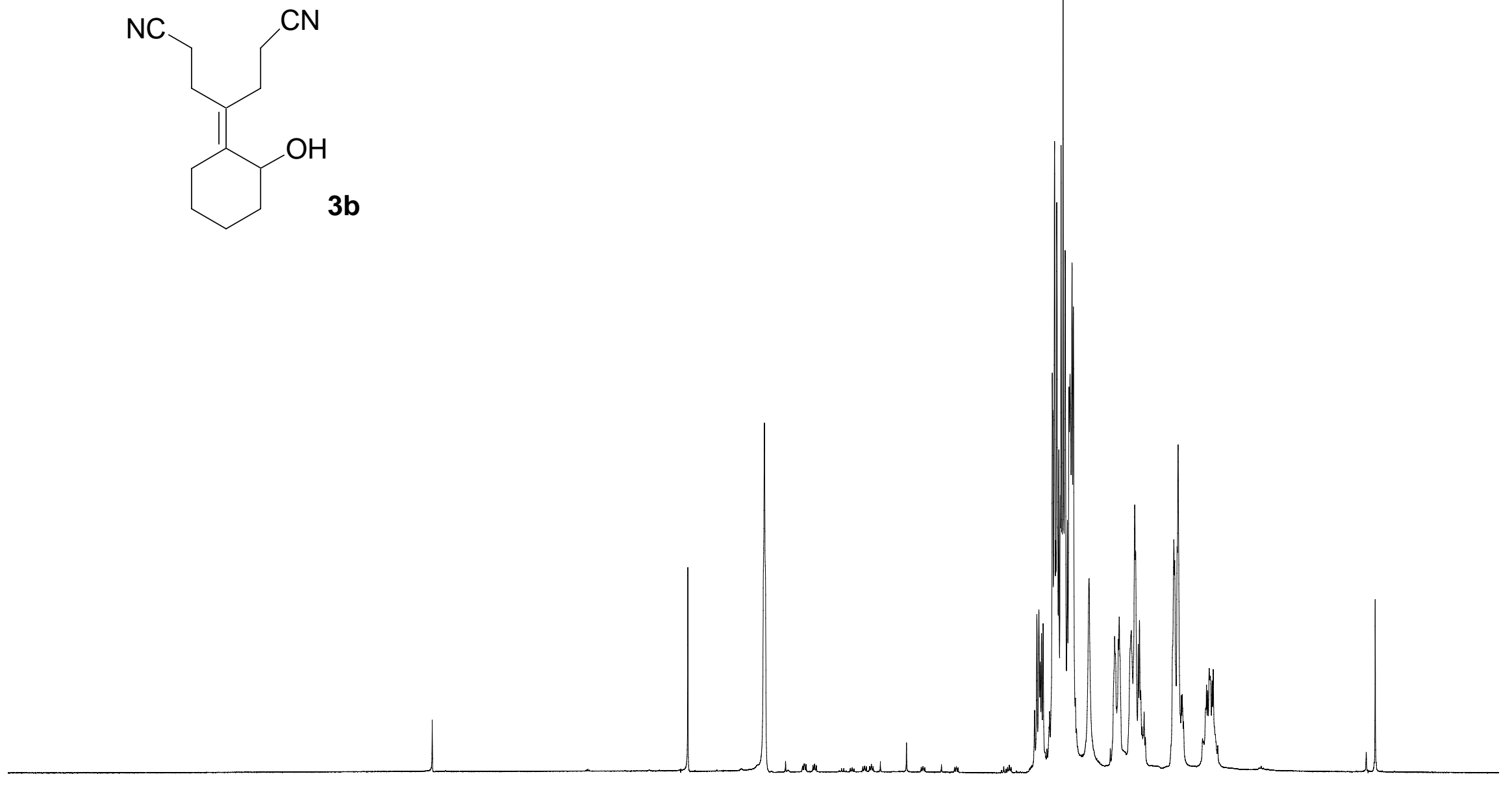

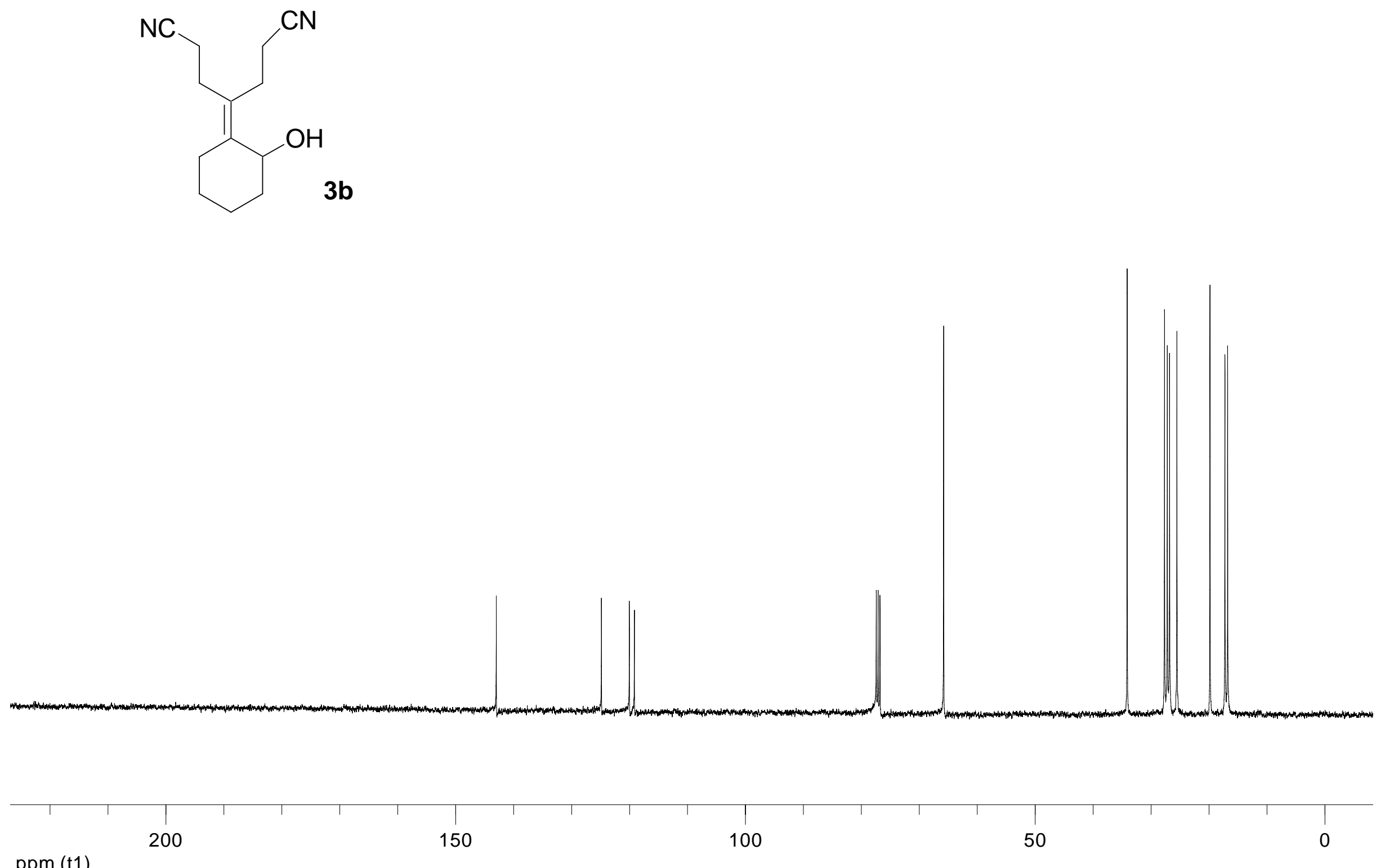

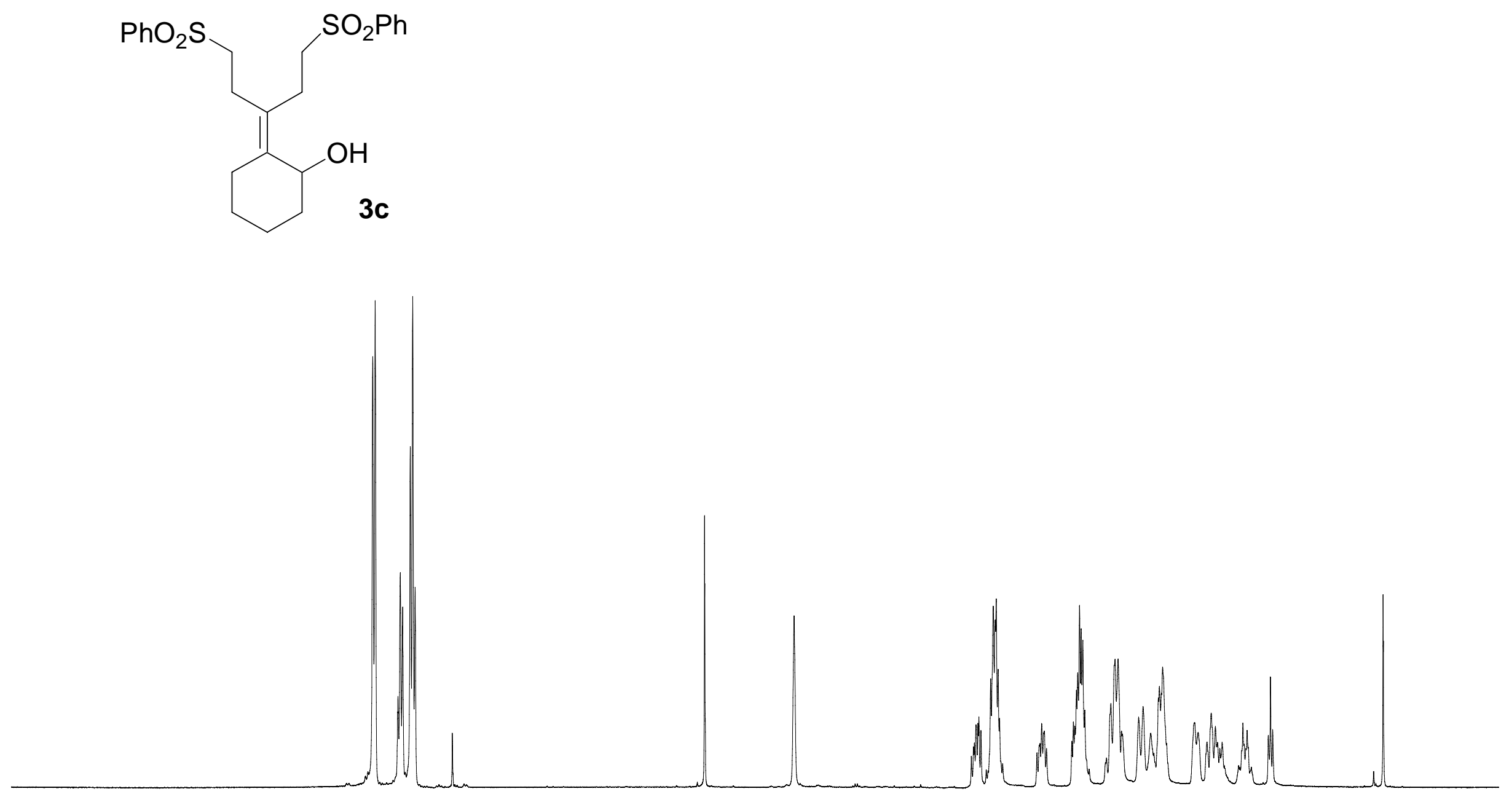

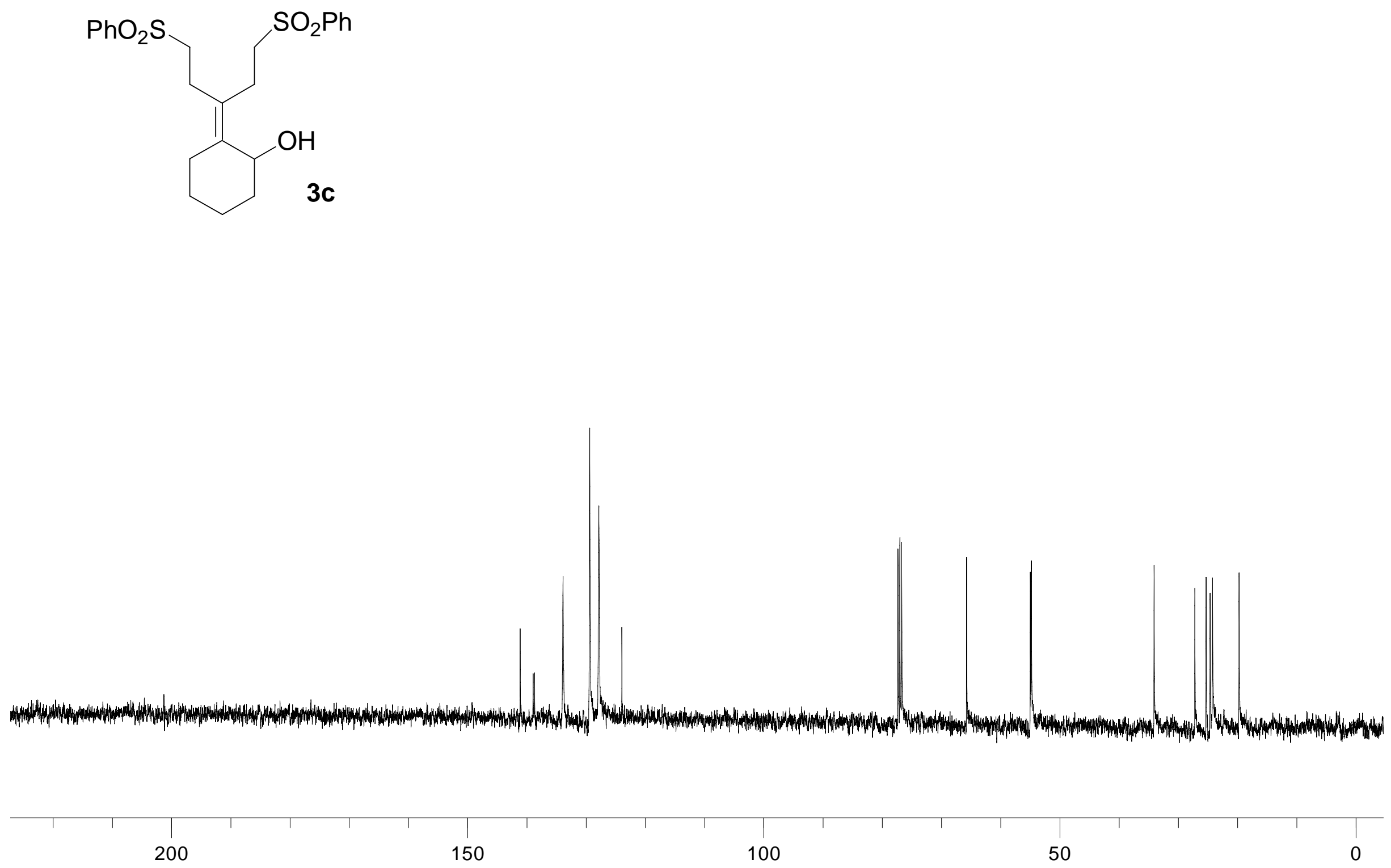

ppm (t1) 

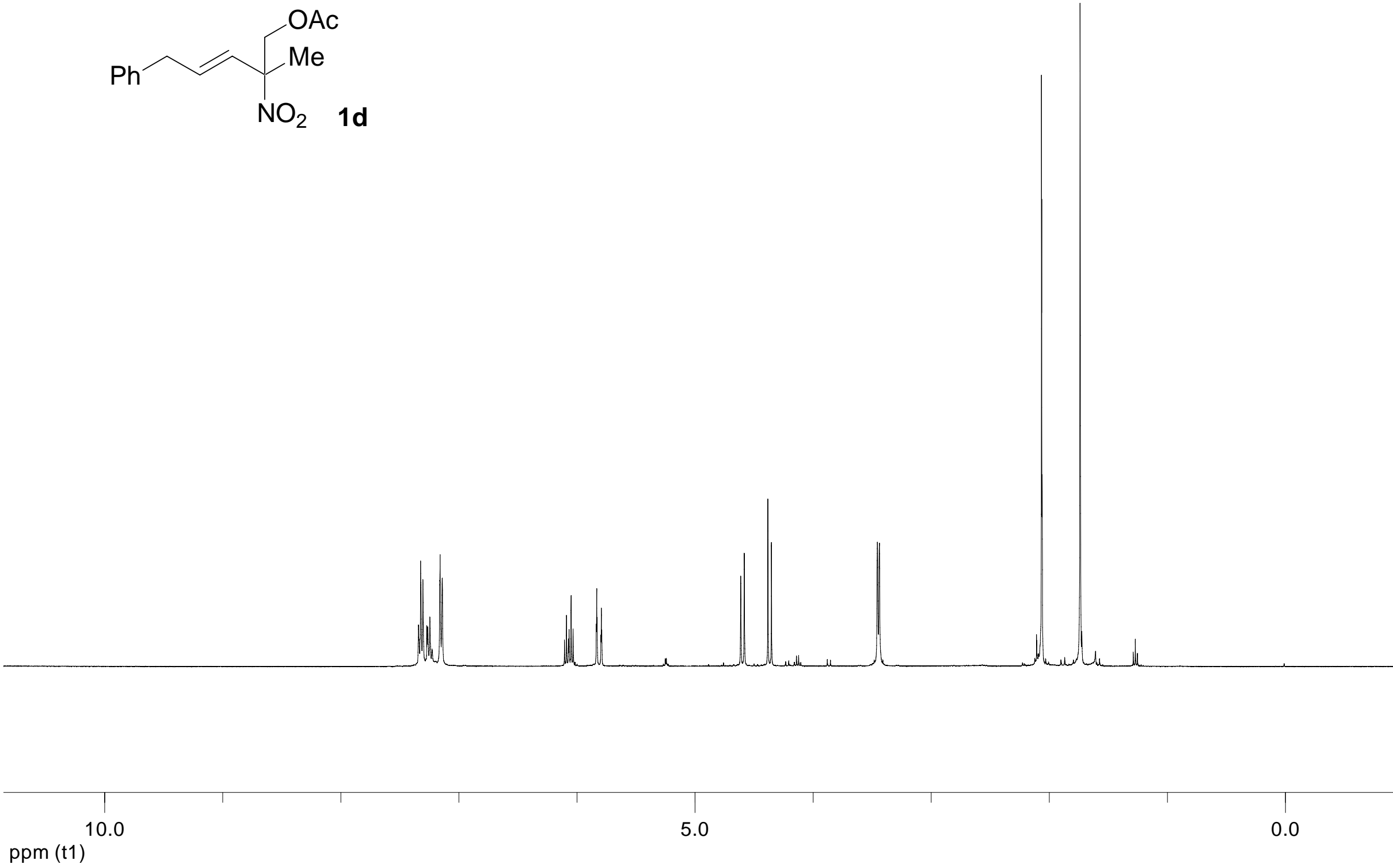

SI 14 


$$
\overbrace{\mathrm{NO}_{2}}^{\mathrm{OAc}} \mathrm{id}
$$
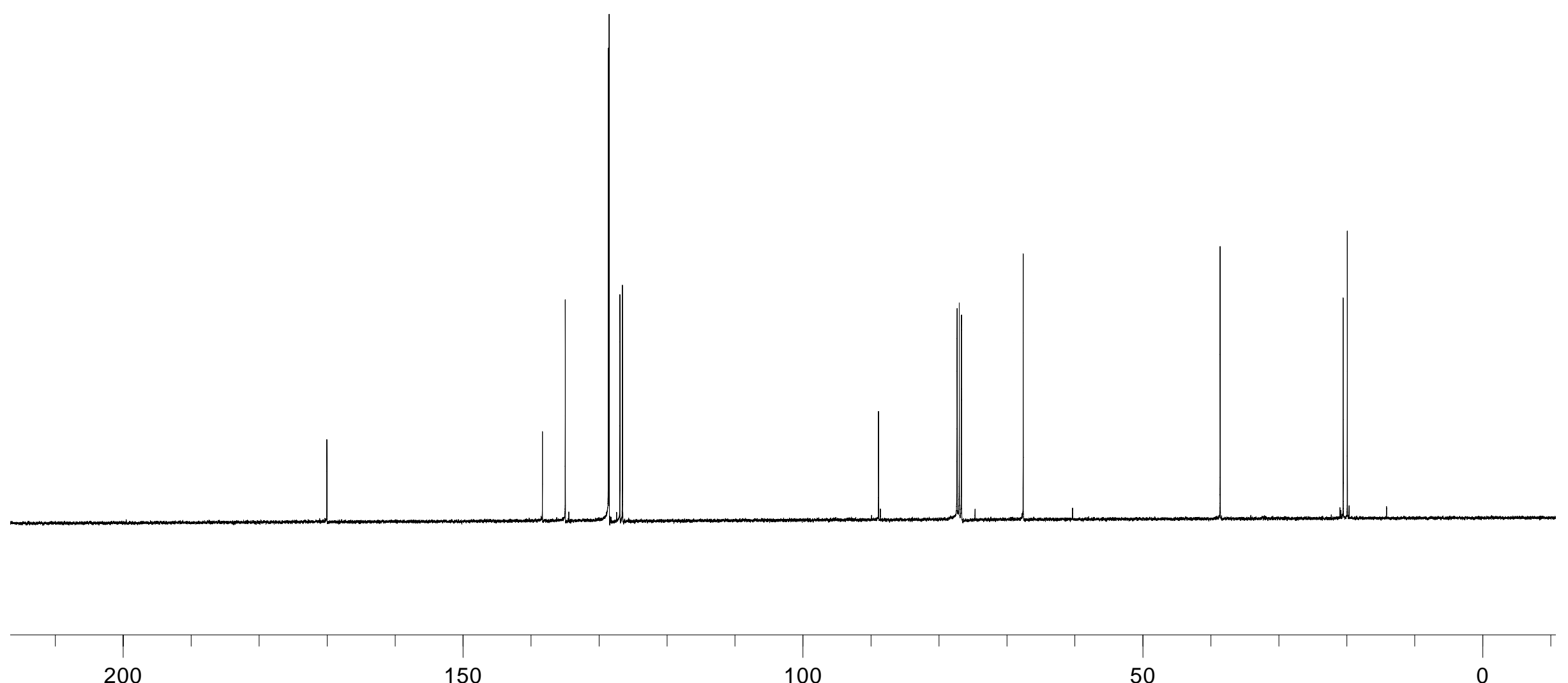

200

150

100

50

ppm (t1)

SI 15 
$\mathrm{Ph}$

$\mathrm{OH} \mathrm{Me}_{3 d}^{\mathrm{OAc}}$

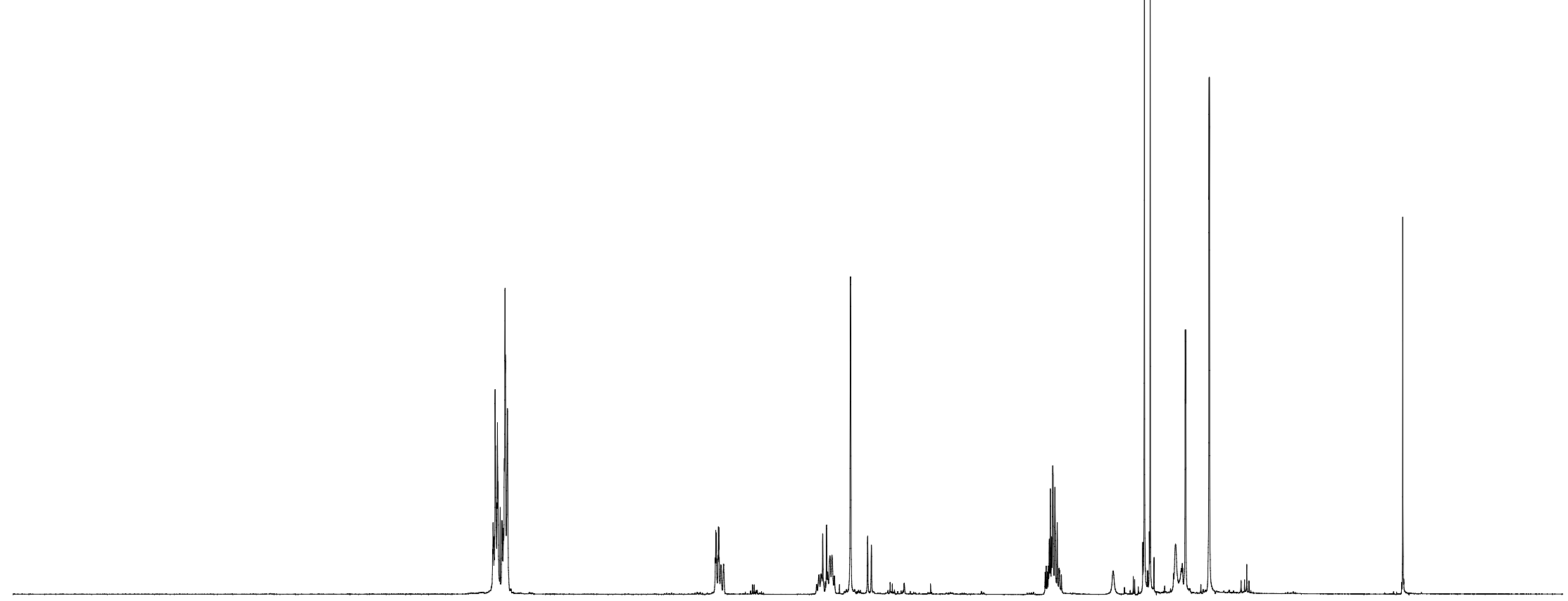

10.0

5.0

0.0

SI 16 

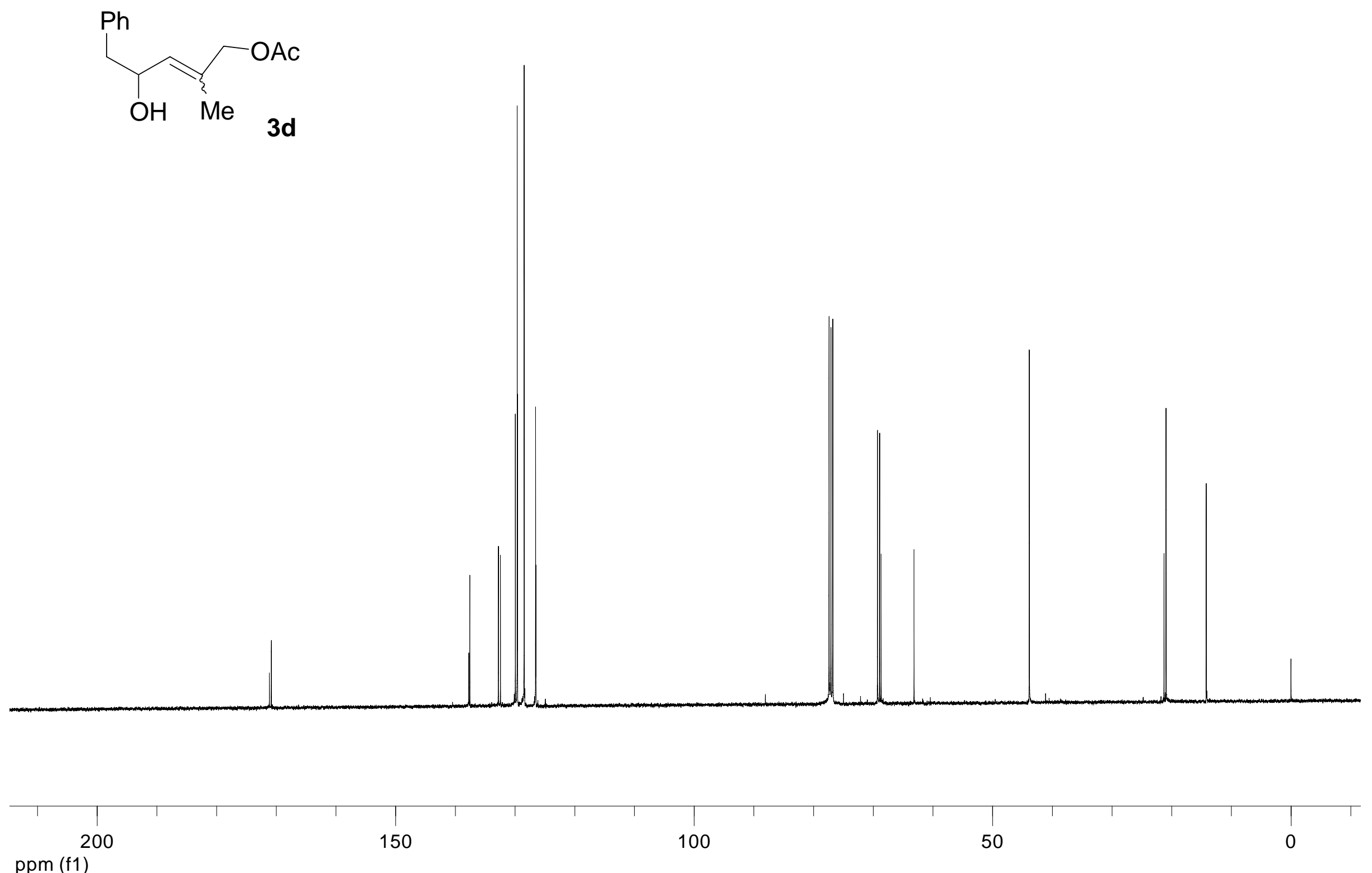

SI 17 


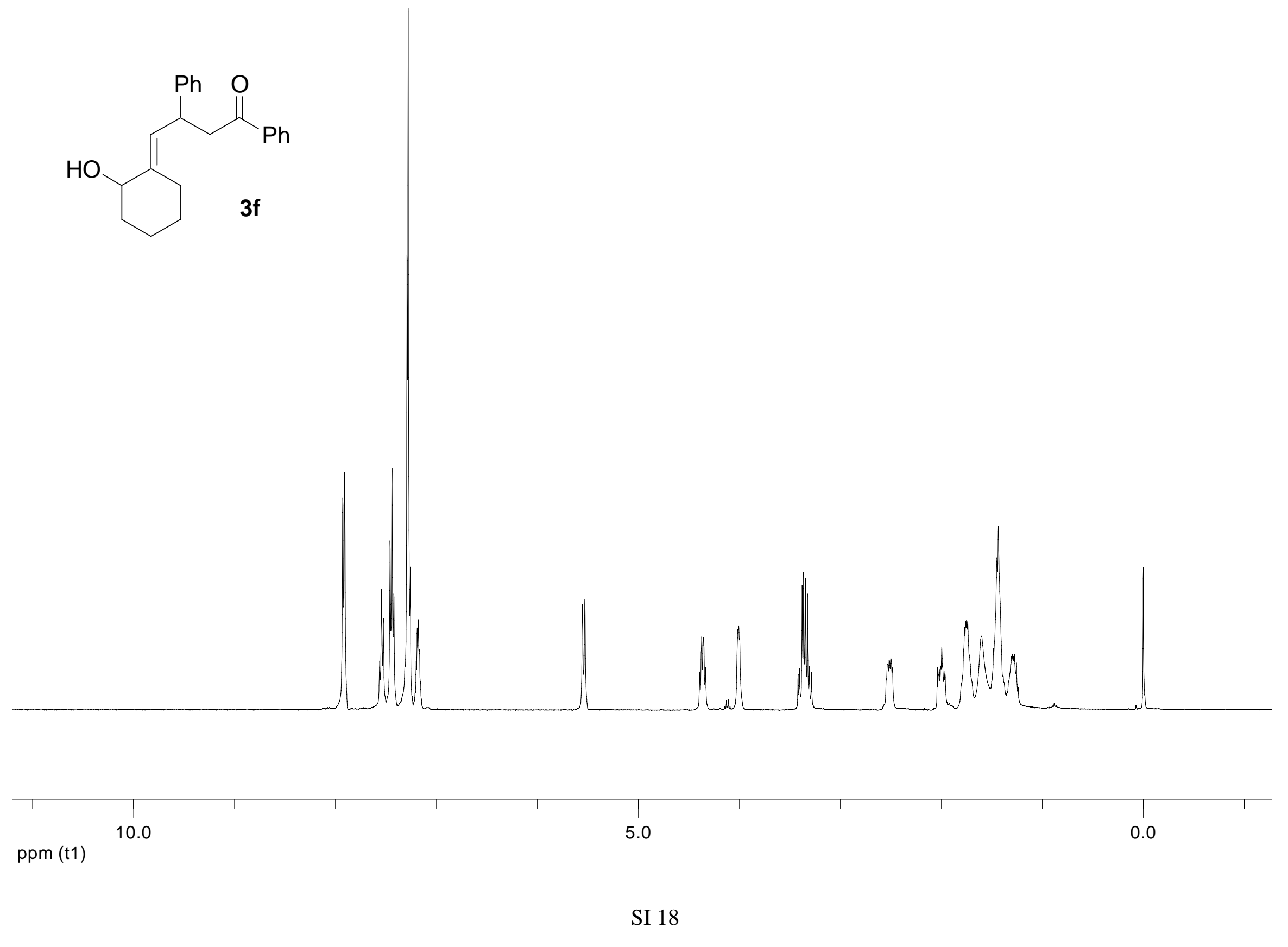



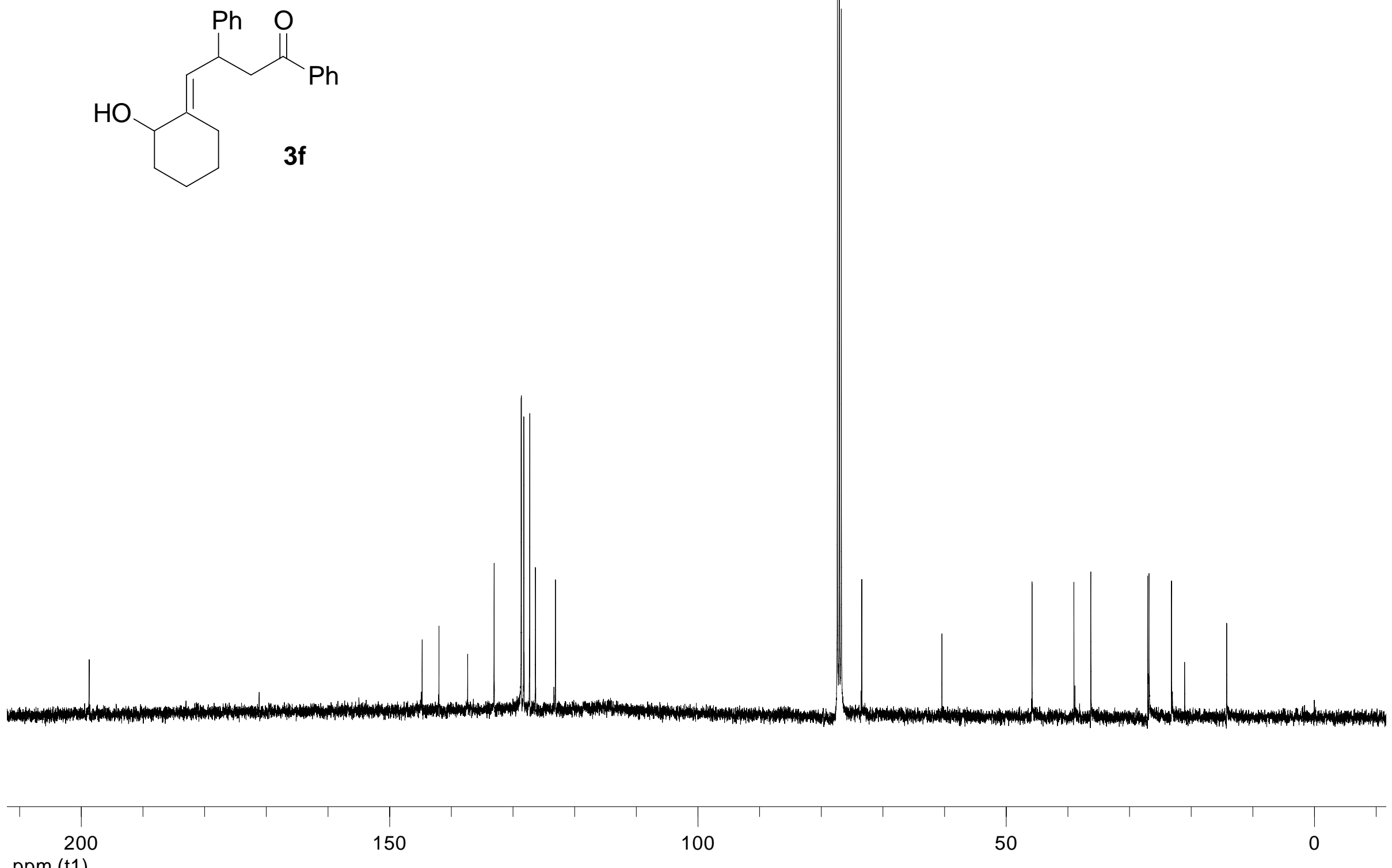
ppm (t1) 

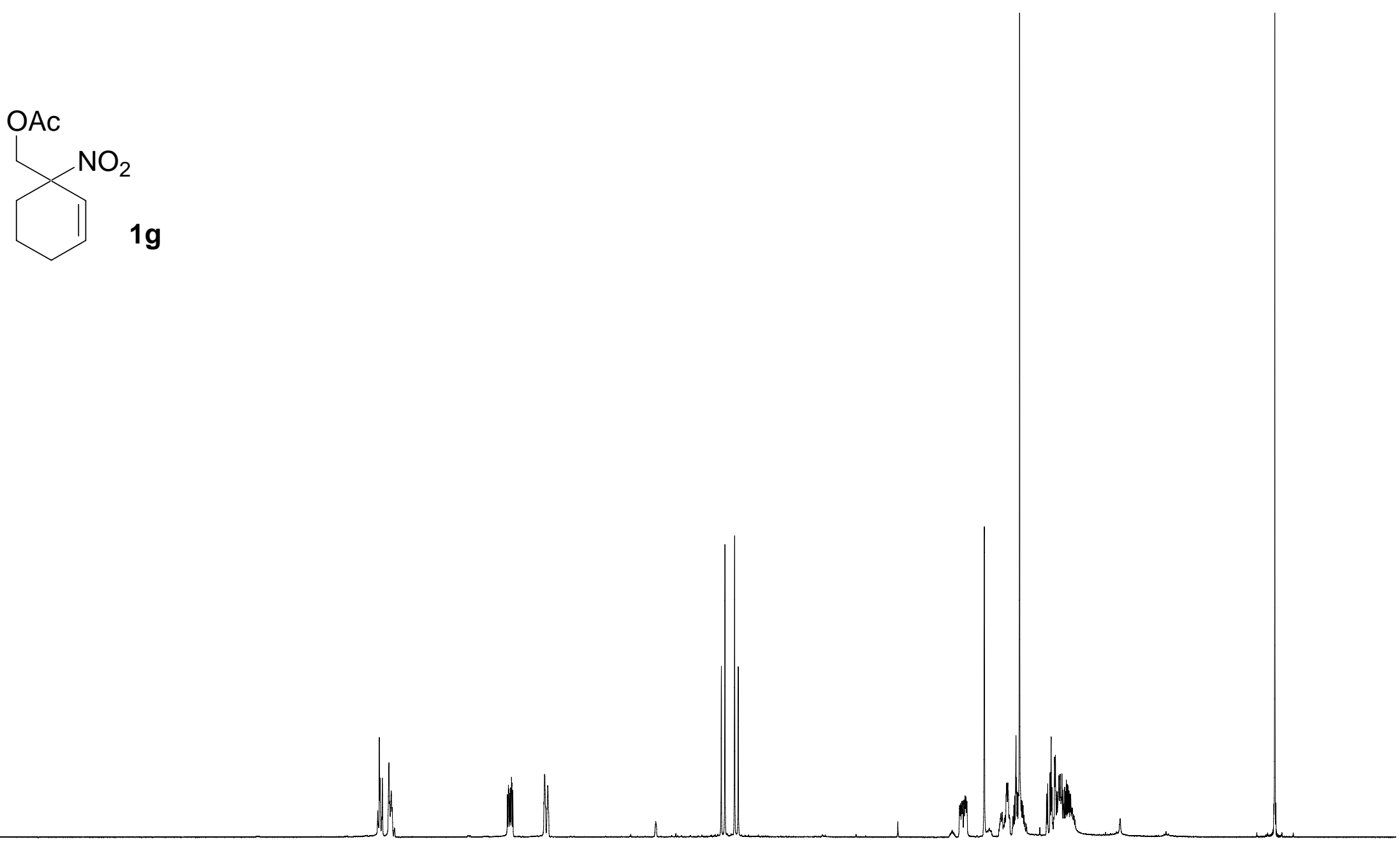

10.0

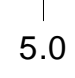

0.0

ppm (t1) 
OAC

$\mathrm{NO}_{2} \mathbf{1 g}$

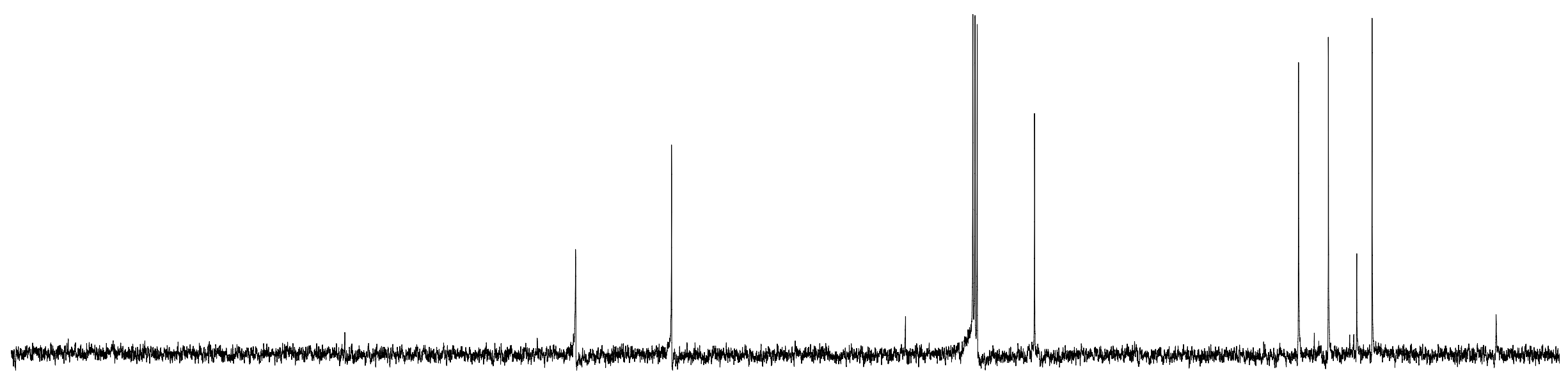

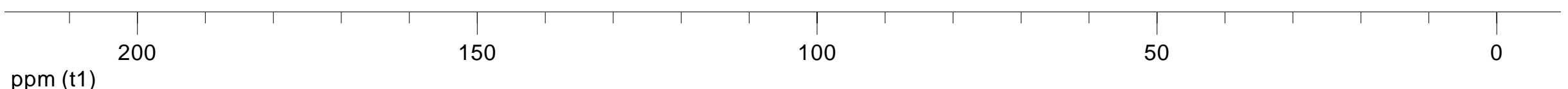




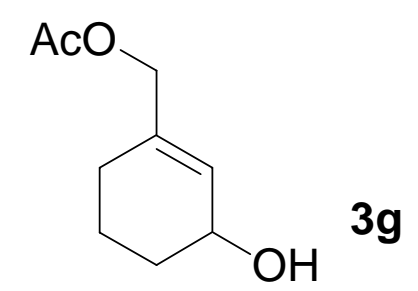

\section{$3 g$}

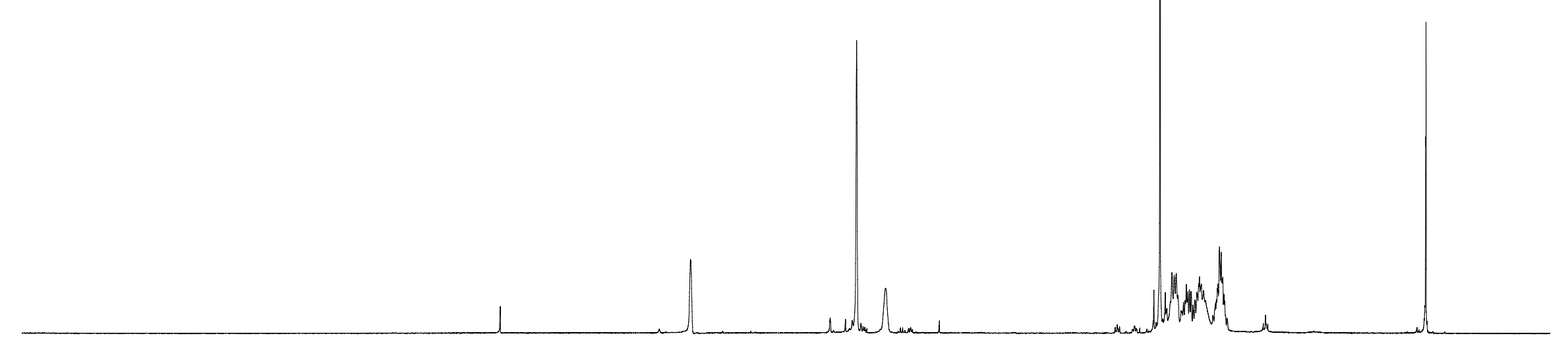

ppm (t1) 10.0 


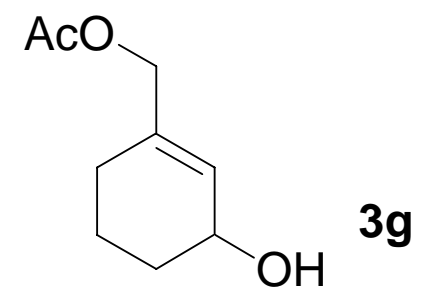

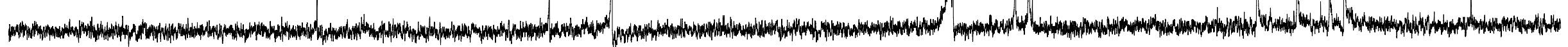

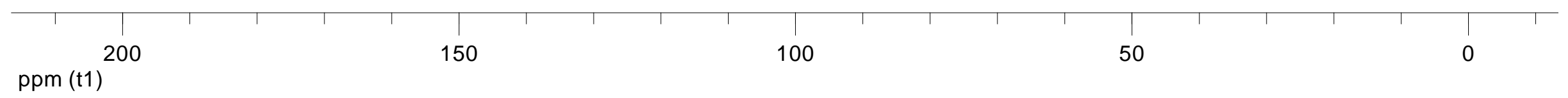



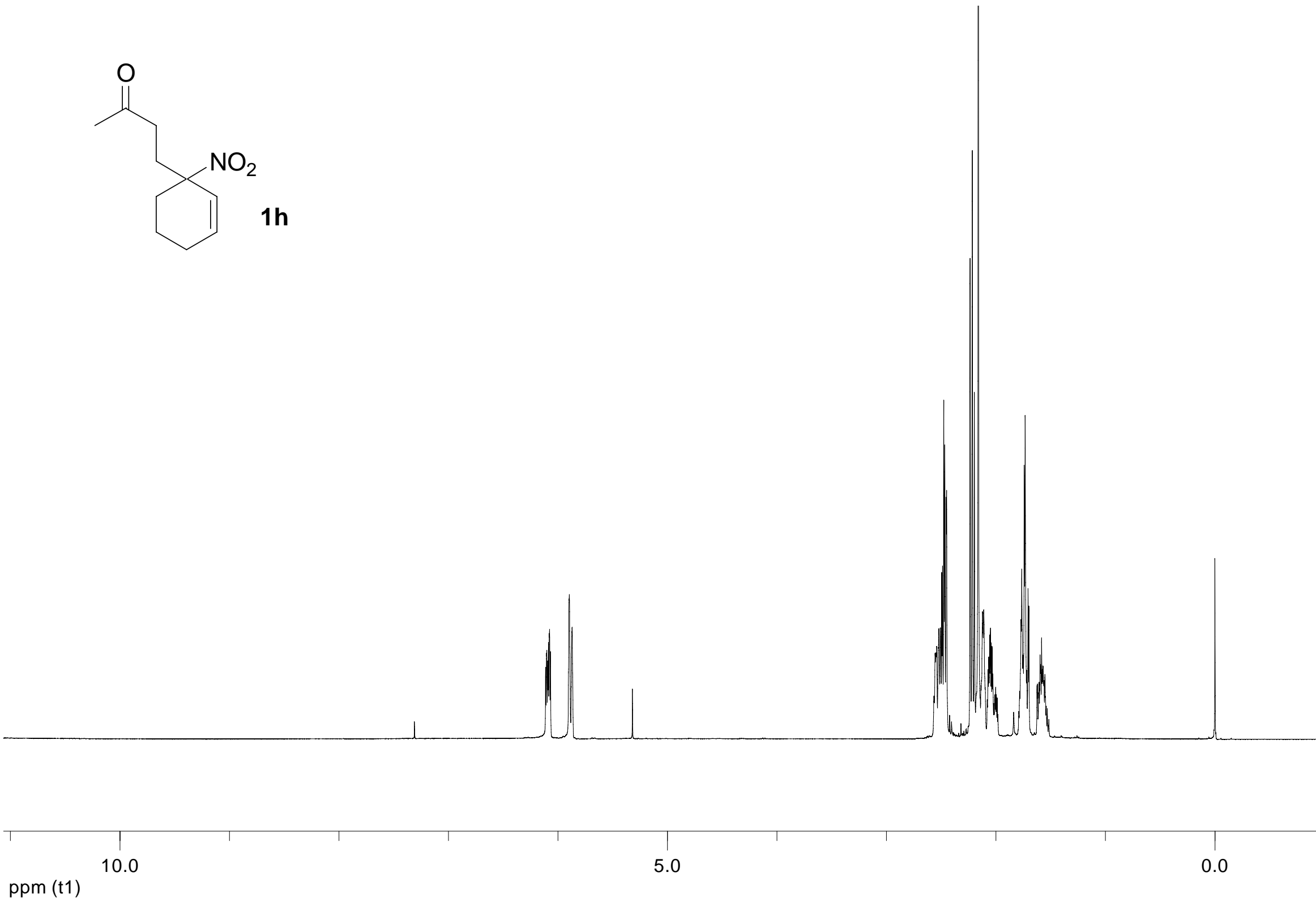

SI 24 


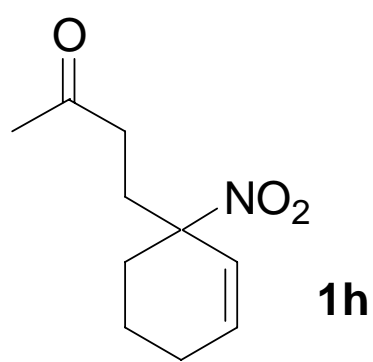

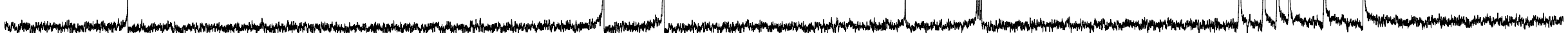

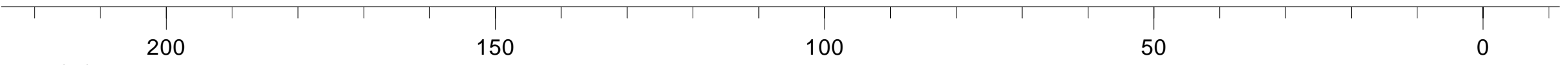

ppm (t1) 


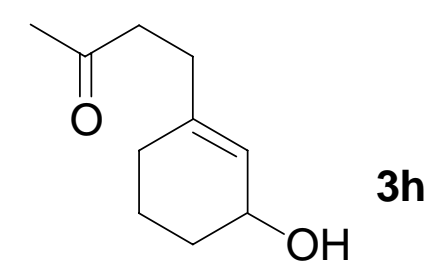

3h

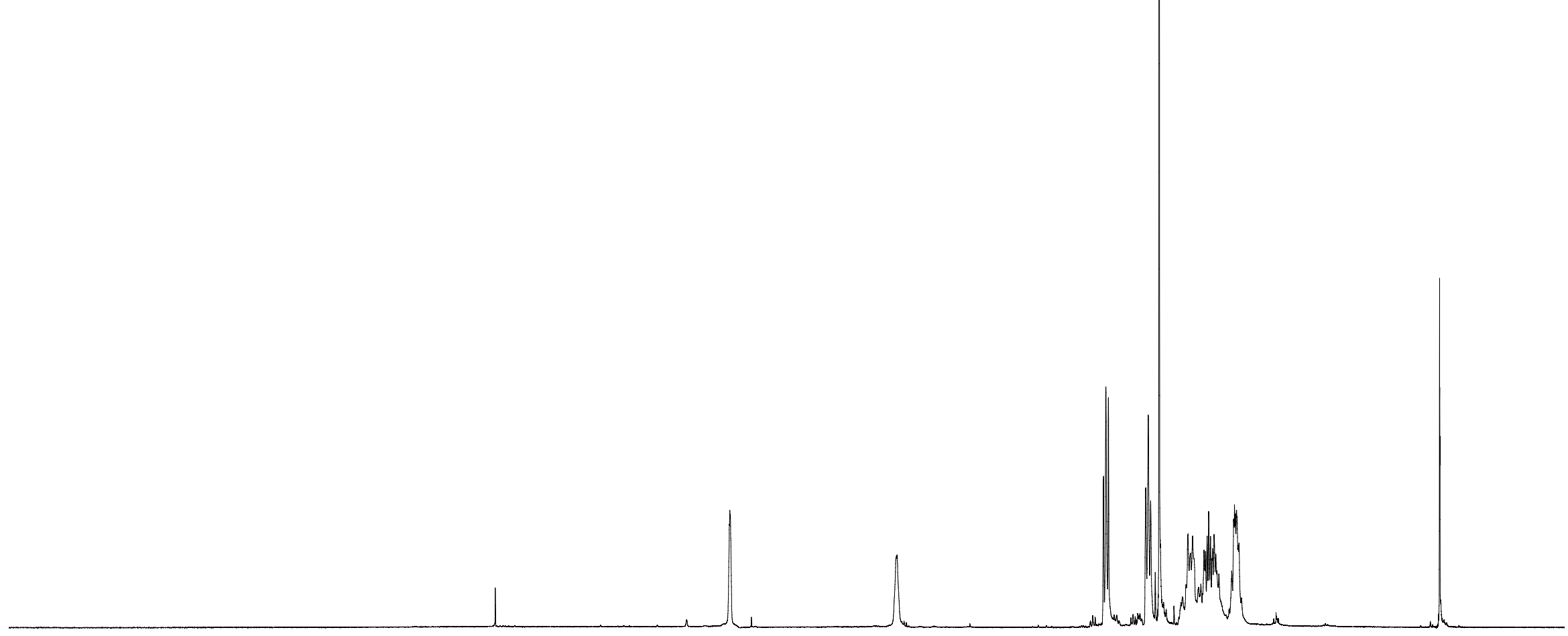

10.0

5.0

0.0

ppm (t1)

SI 26 

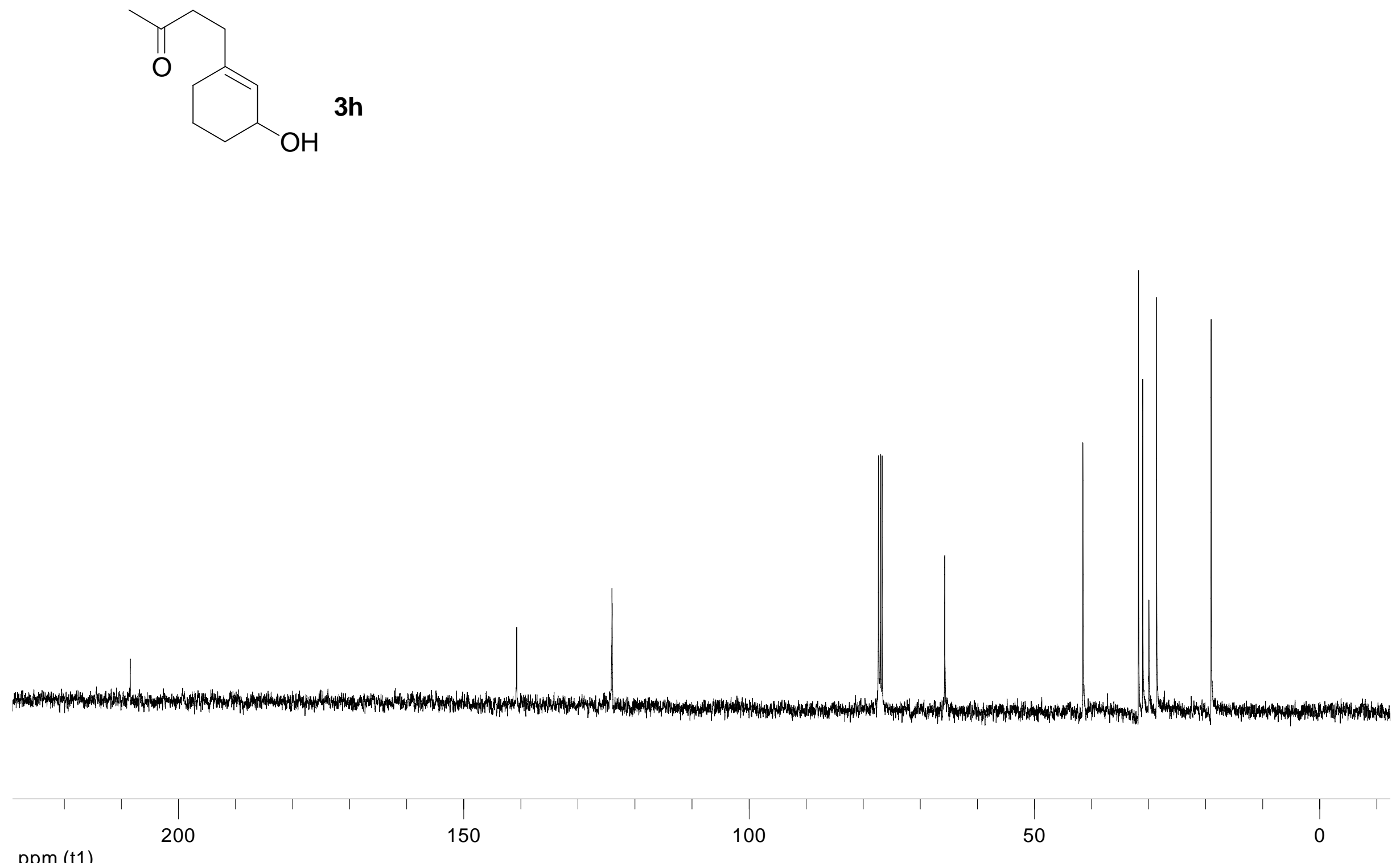

ppm (t1) 


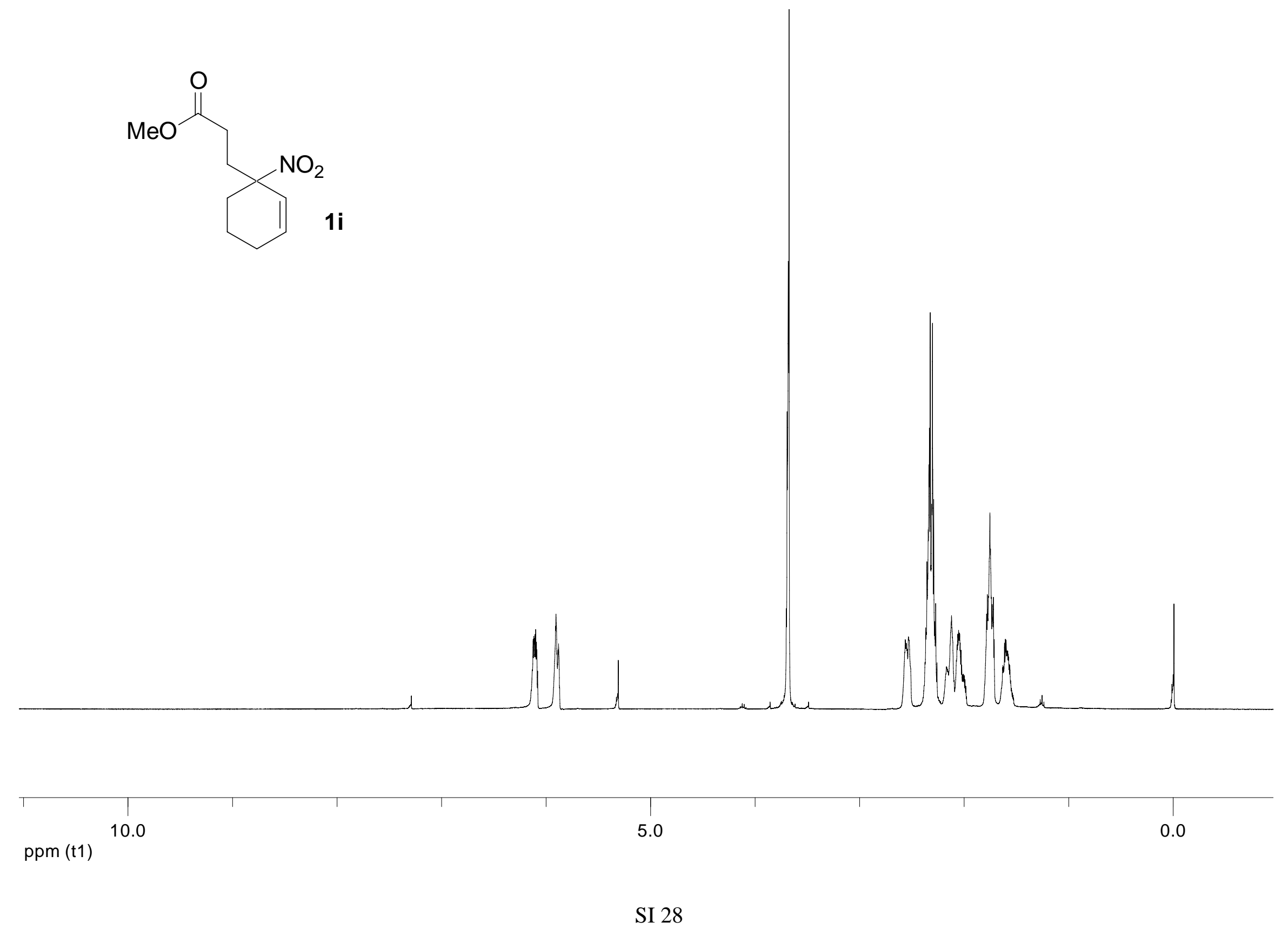



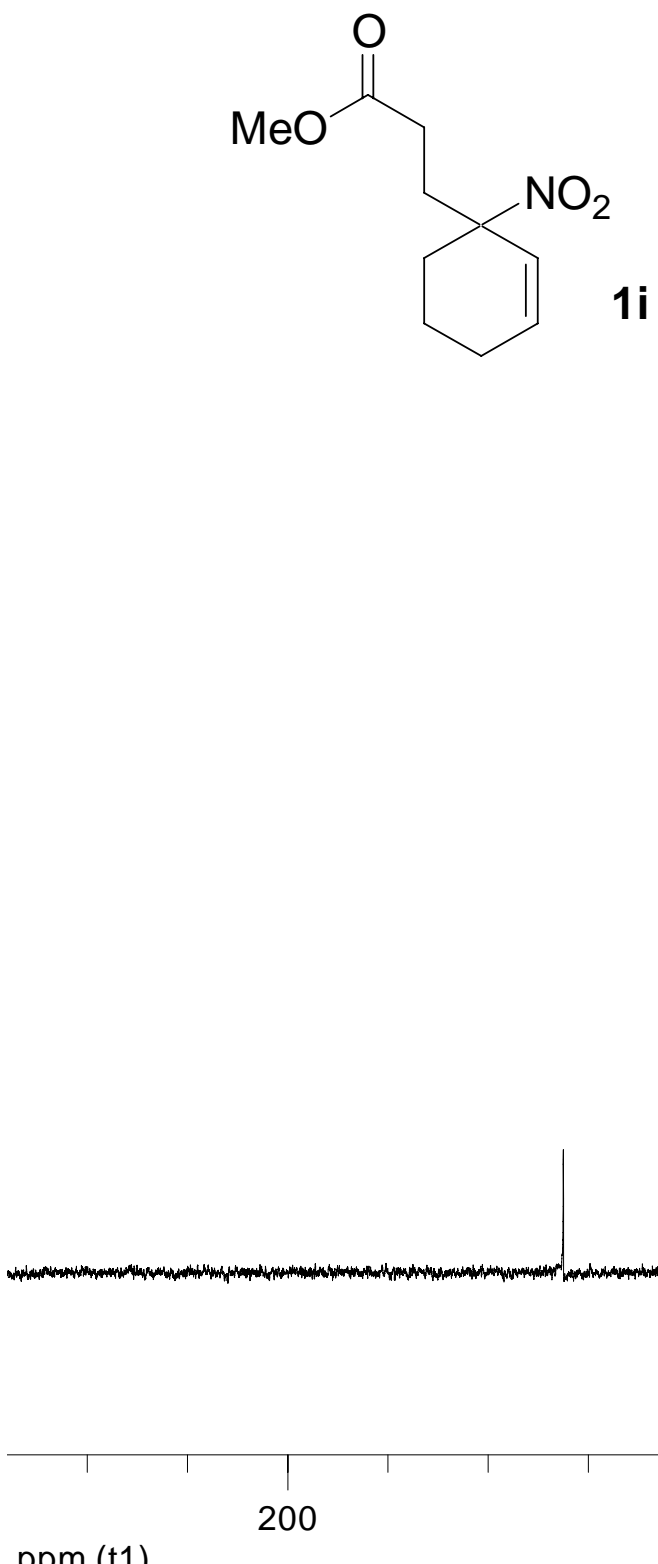


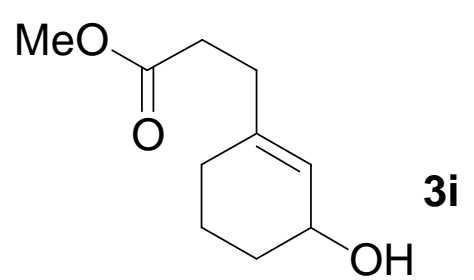

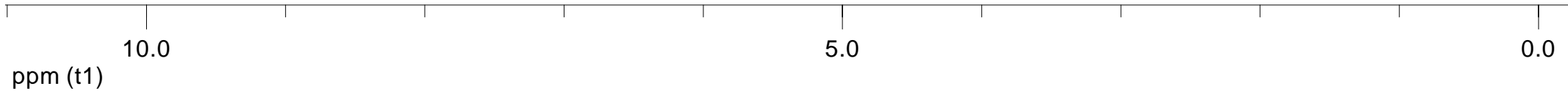



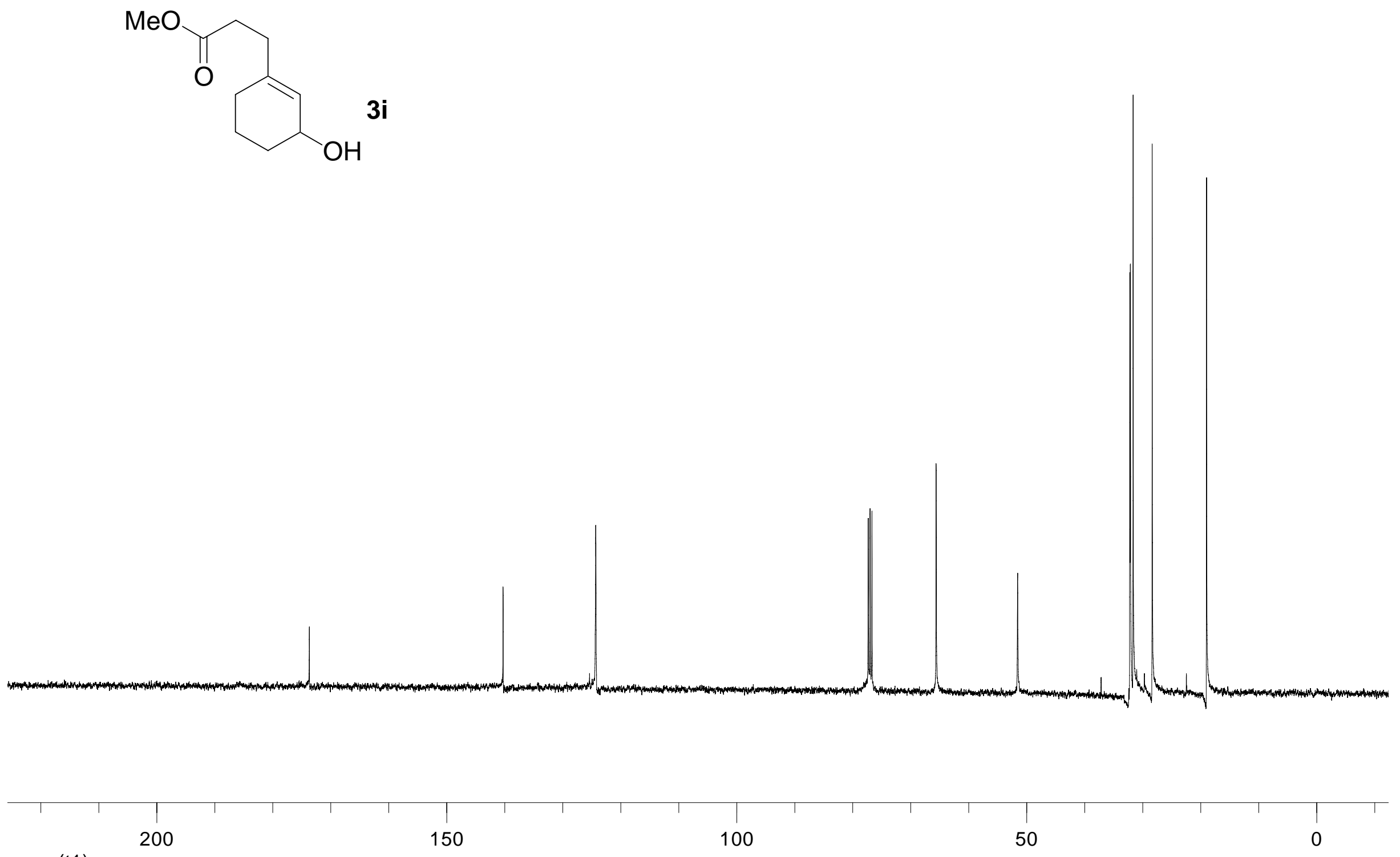

ppm (t1) 
$\sum_{\mathbf{i j}}^{\mathrm{PhO}_{2} \mathrm{~S}} \mathrm{NO}_{2}$

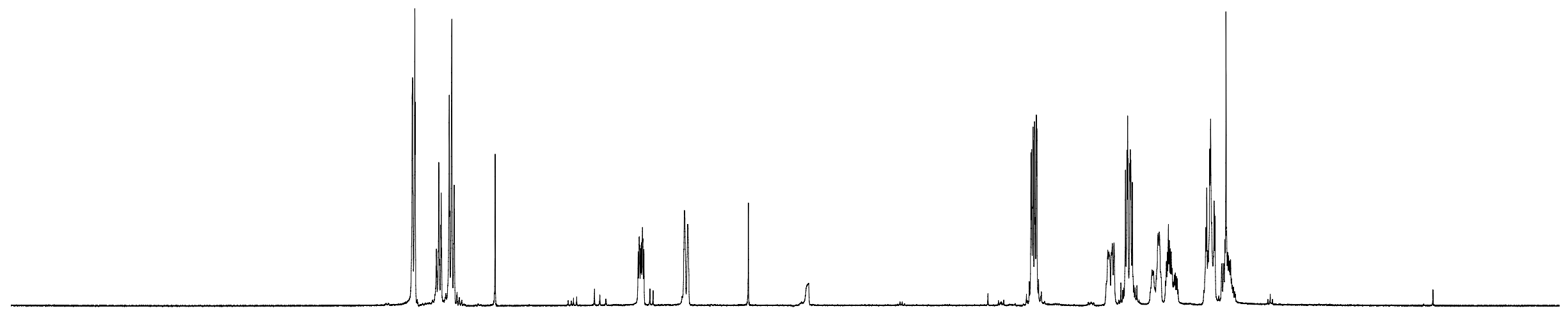

SI 32 
$\mathrm{PhO}_{2} \mathrm{~S} \mathrm{NO}_{\mathbf{i j}}^{\mathrm{NO}_{2}}$

M.

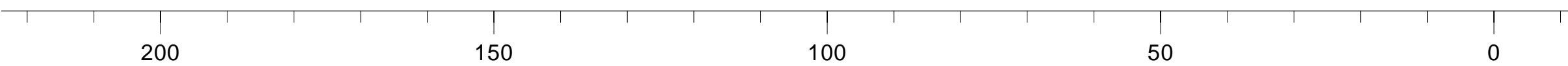

ppm (t1) 
$\overbrace{\mathrm{OH}^{3}}^{\mathrm{PhO}_{2} \mathrm{~S}}$
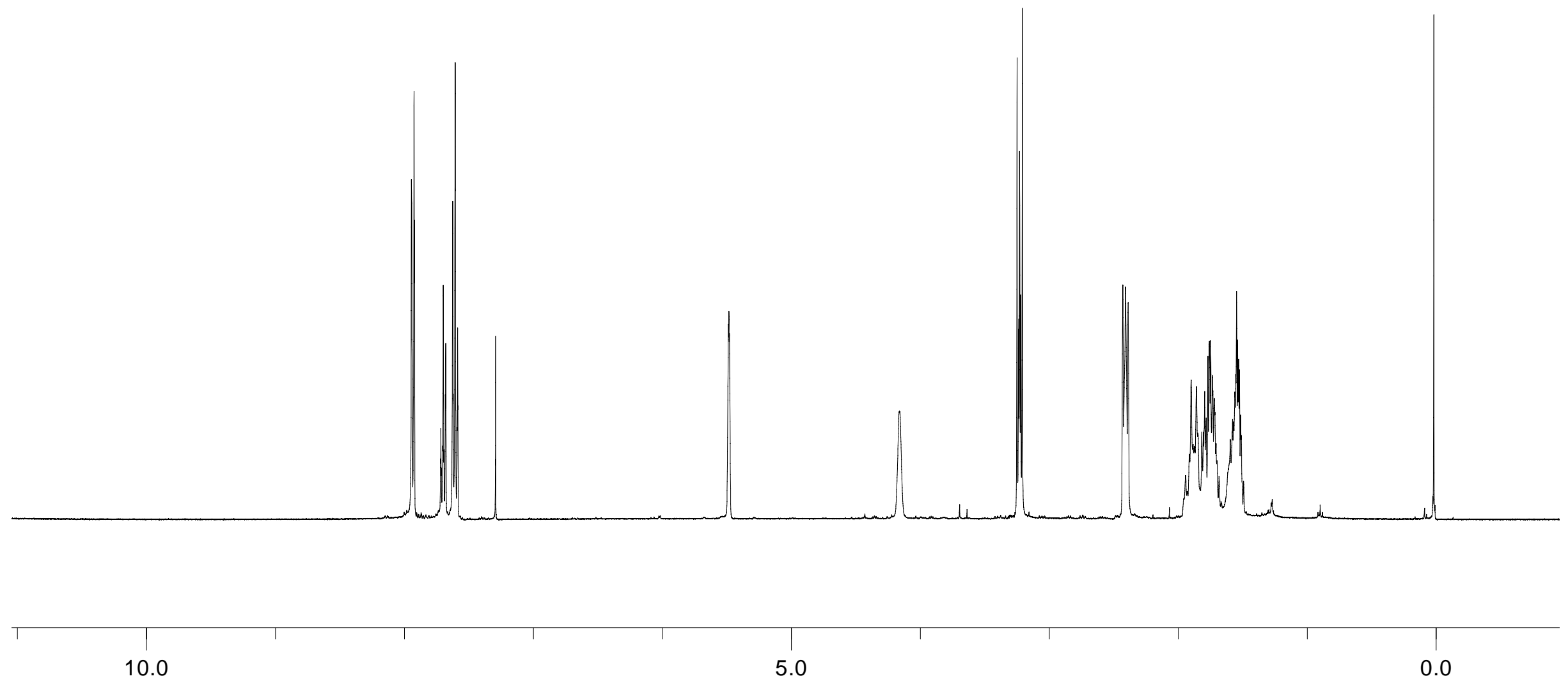

10.0

5.0

0.0

ppm (t1)

SI 34 
$\overbrace{\mathrm{OH}^{3 j}}^{\mathrm{PhO}_{2} \mathrm{~S}}$

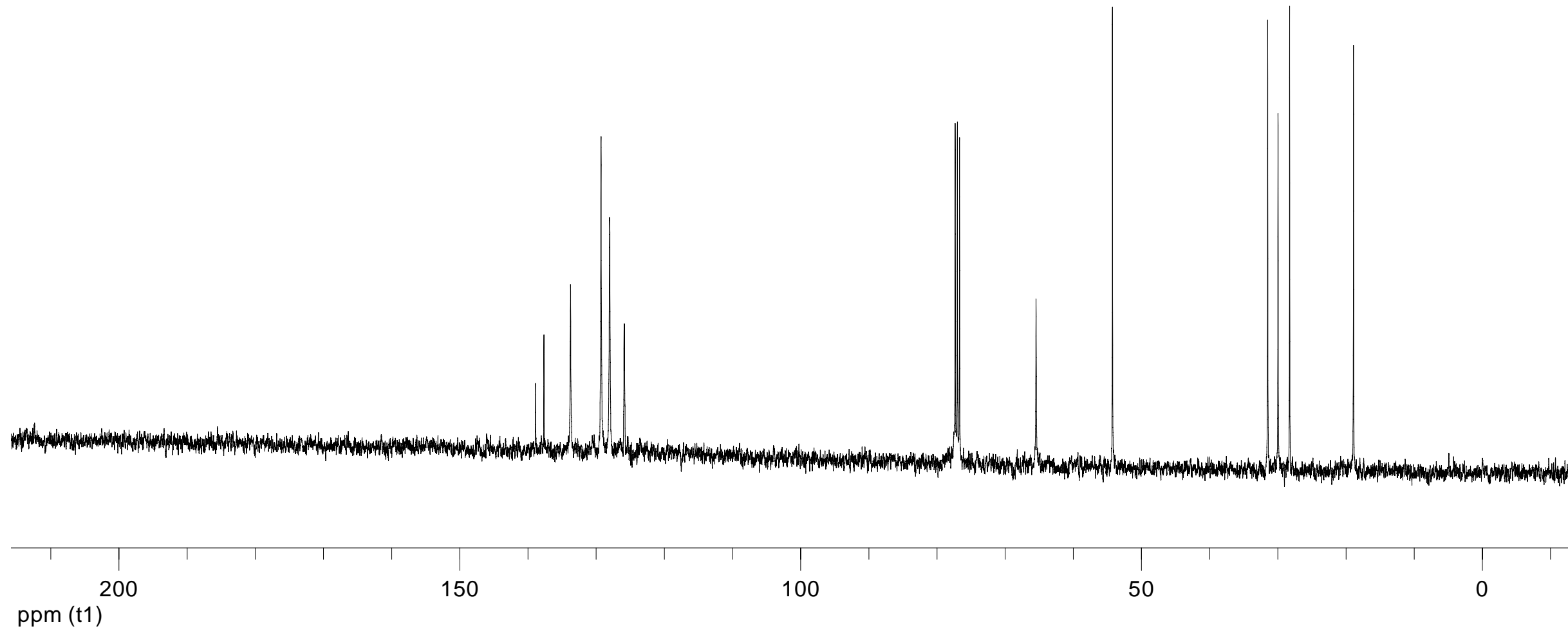



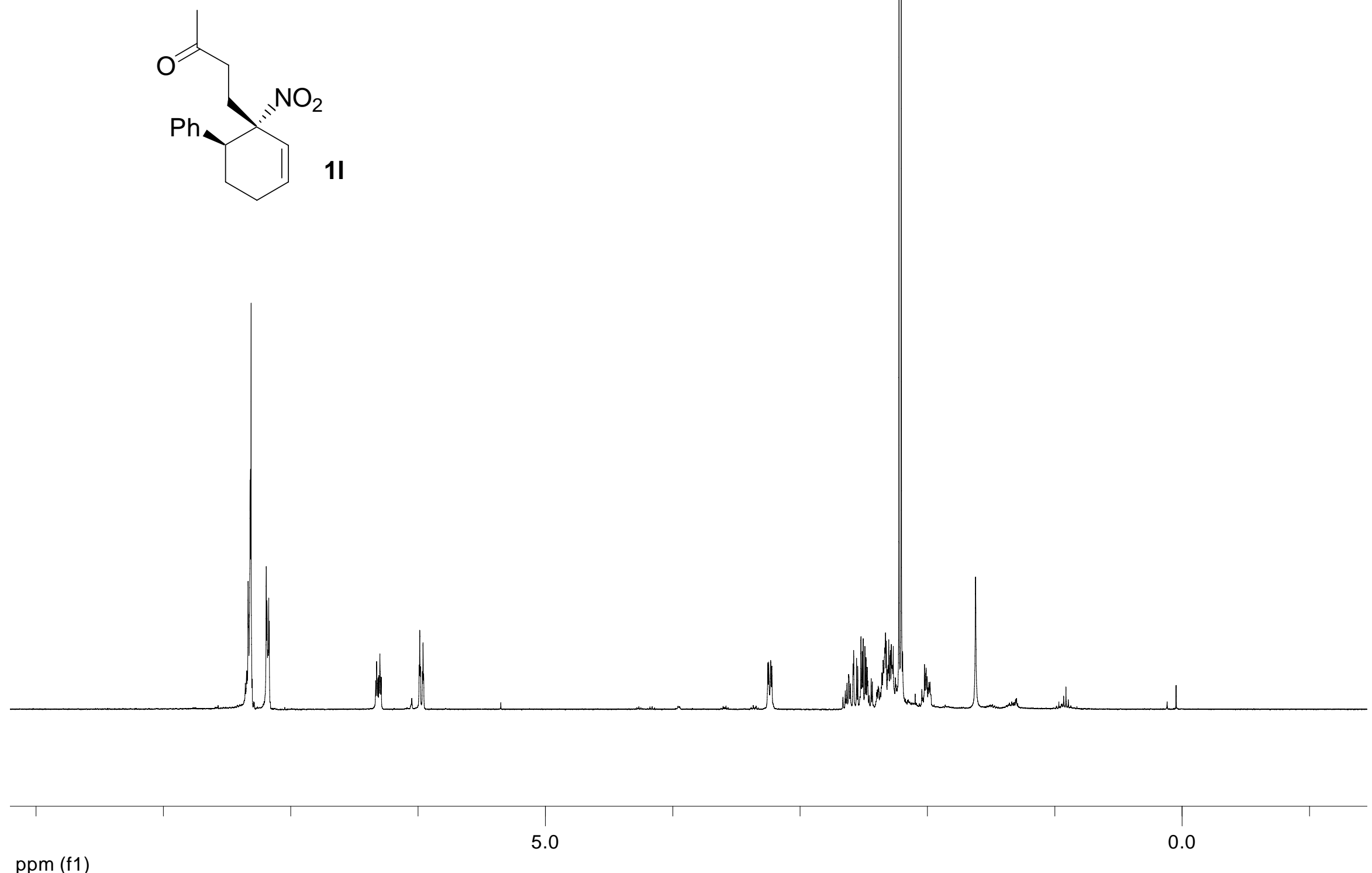

SI 36 


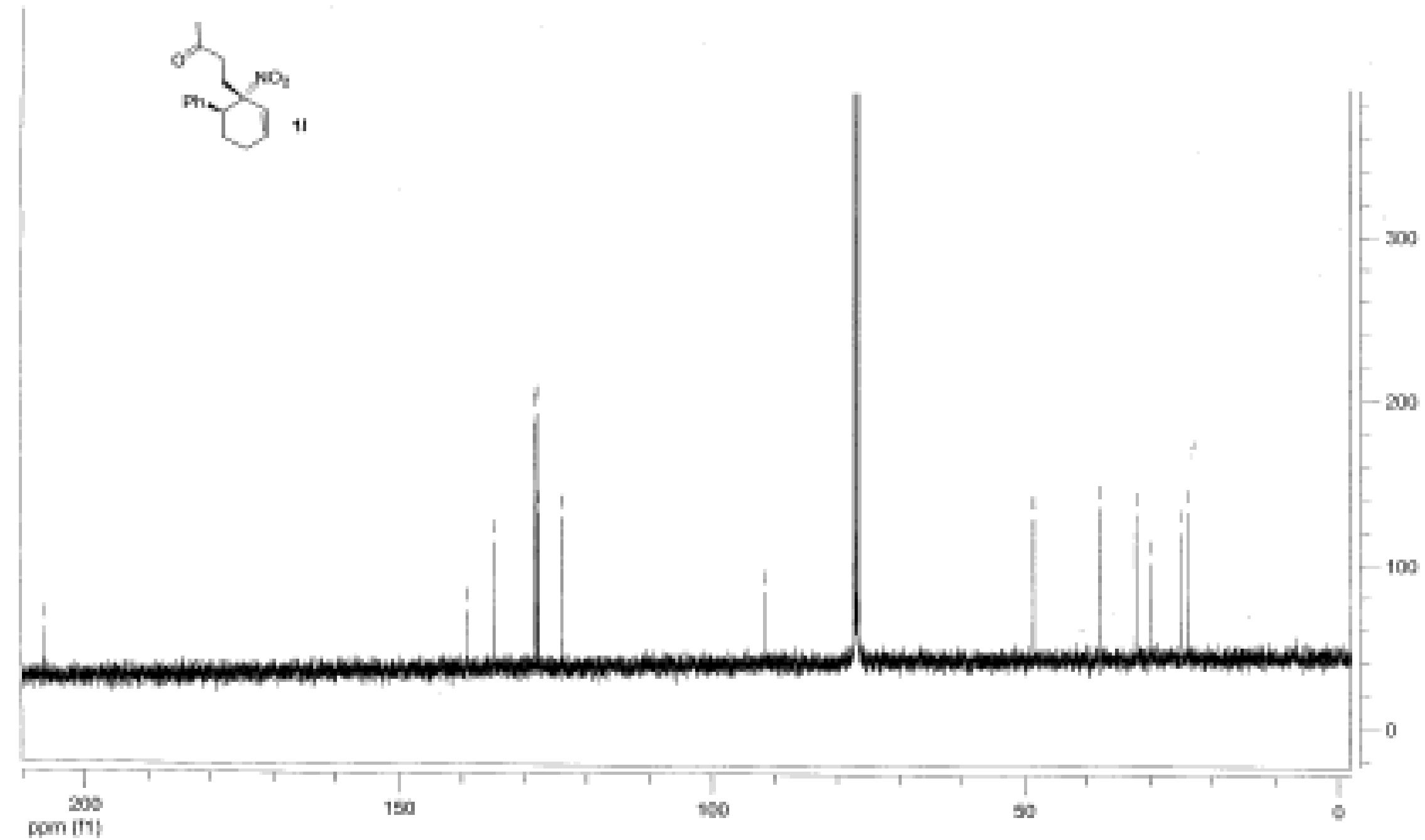




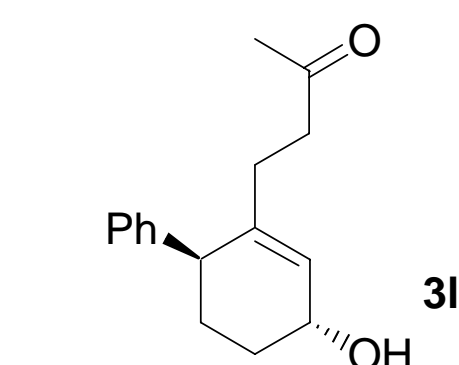

31

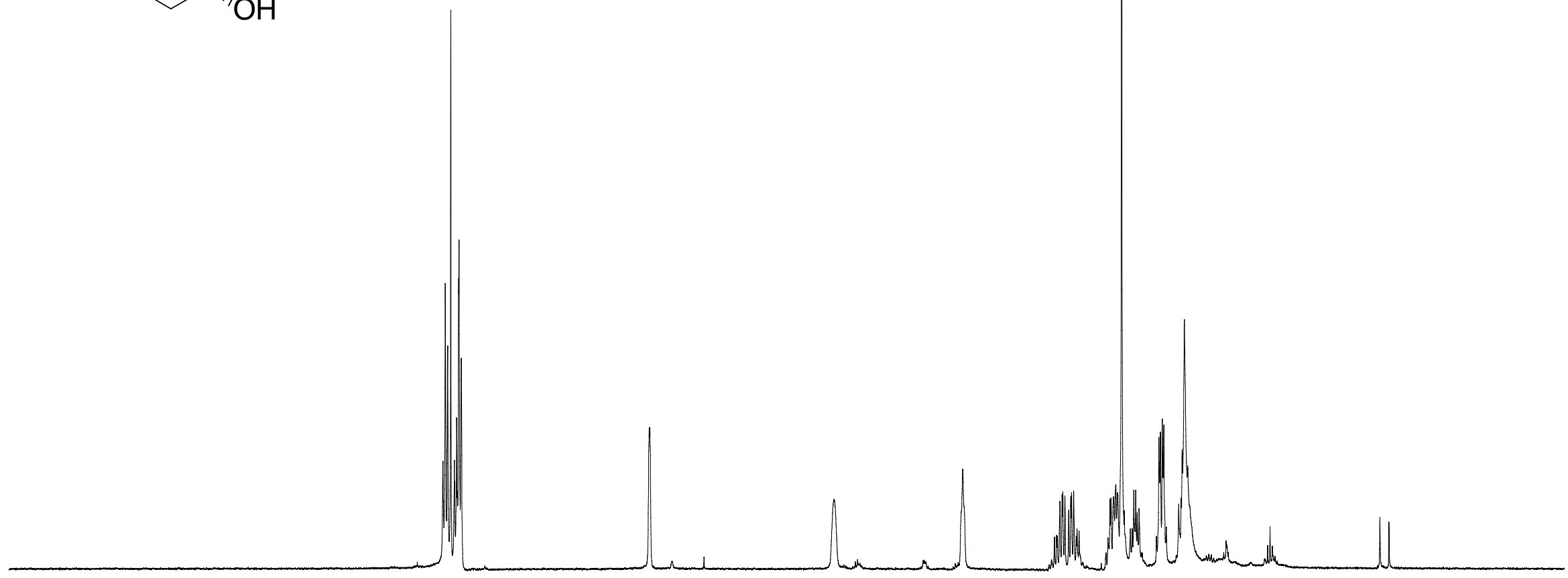

10.0 

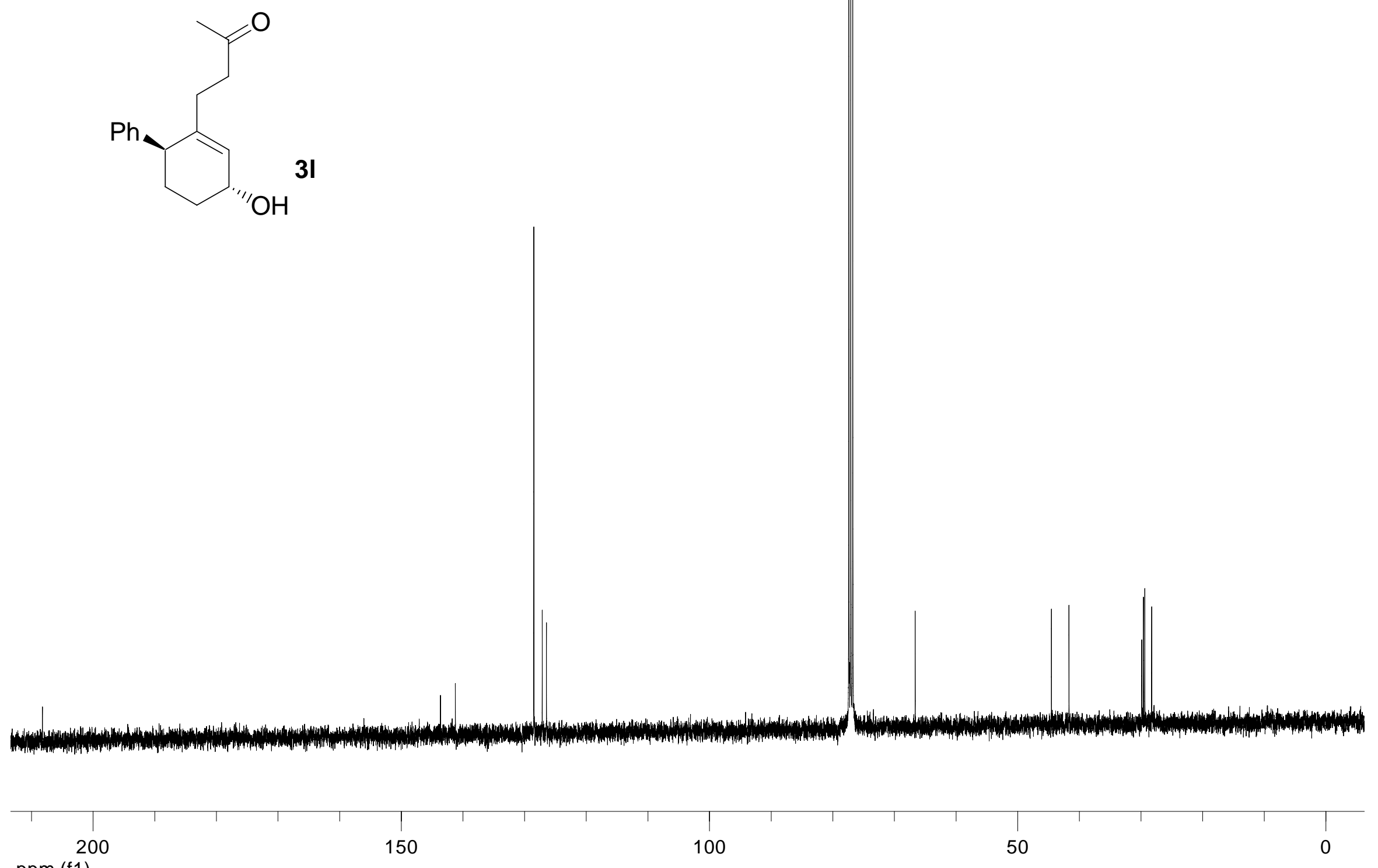

ppm (f1) 
$\mathrm{PhO}_{2} \mathrm{~S}$
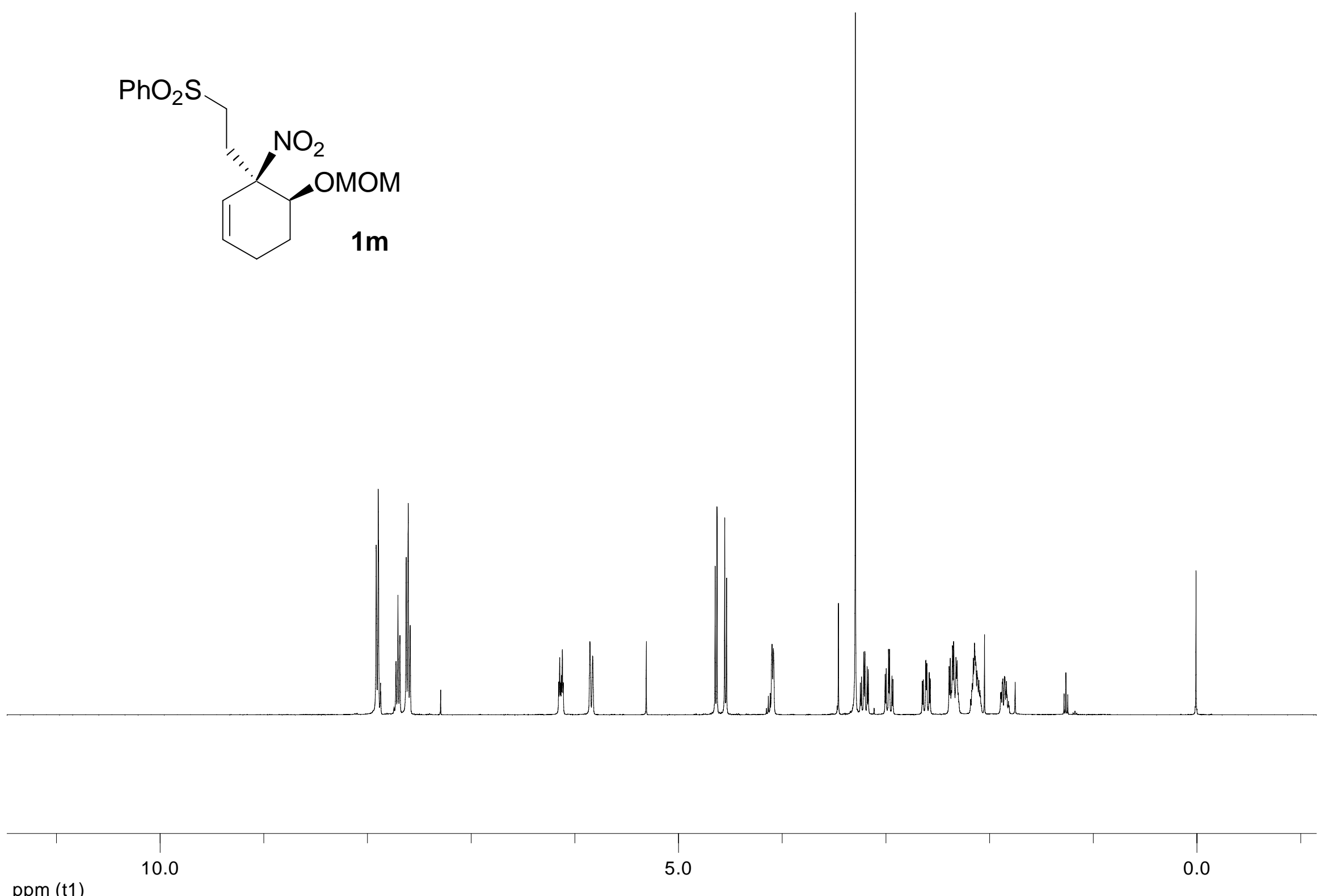

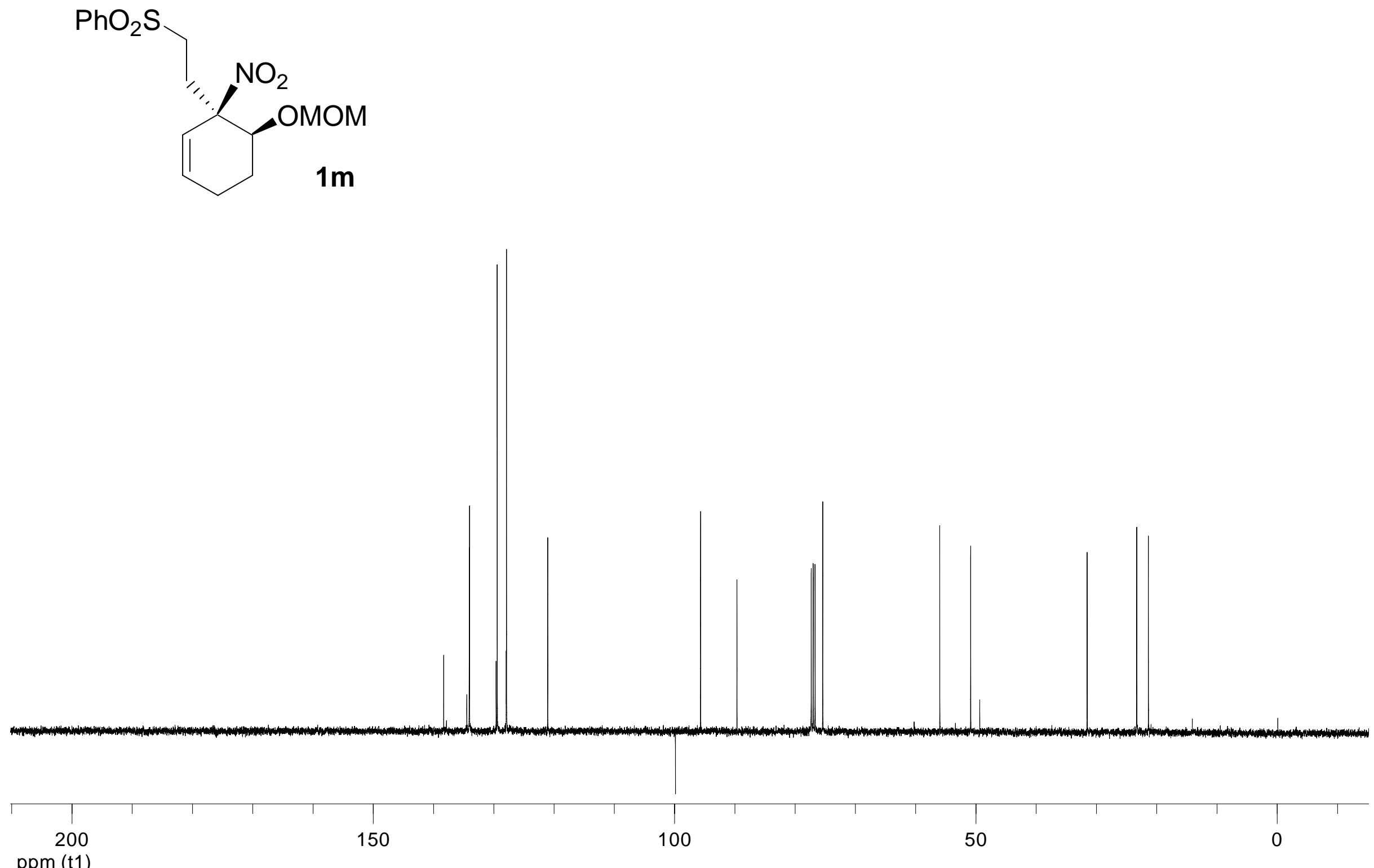
ppm (t1) 

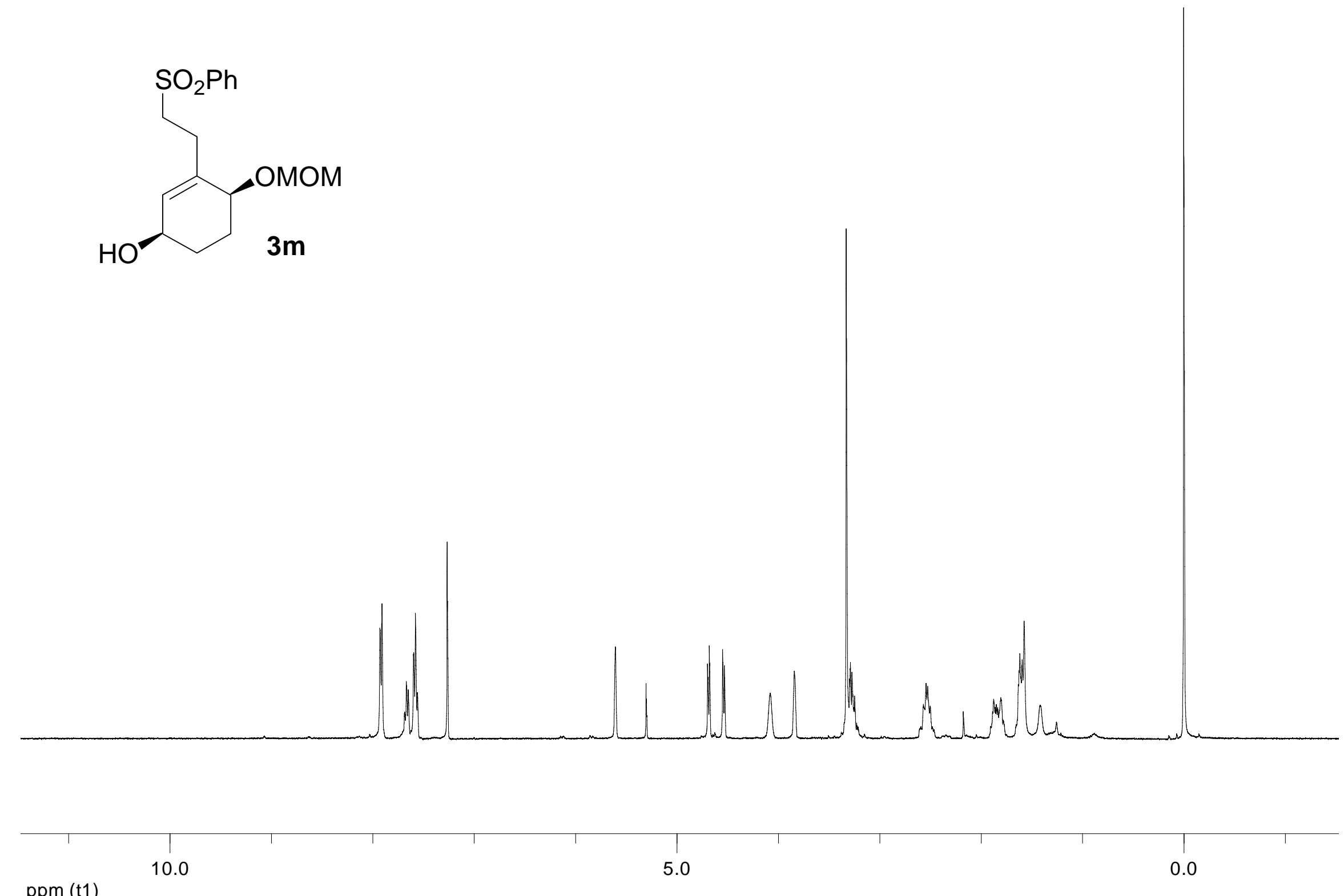

ppm (t1) 

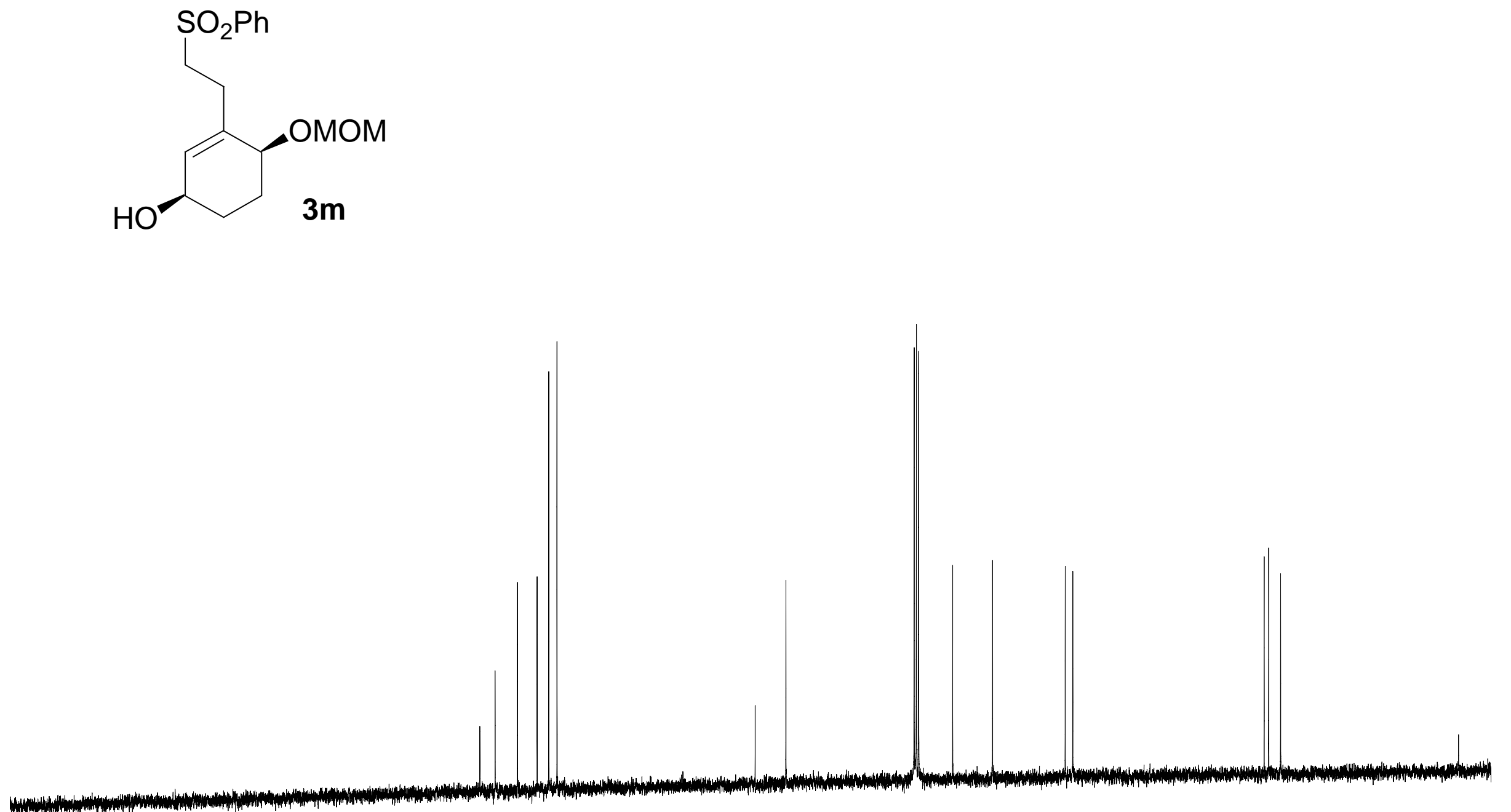

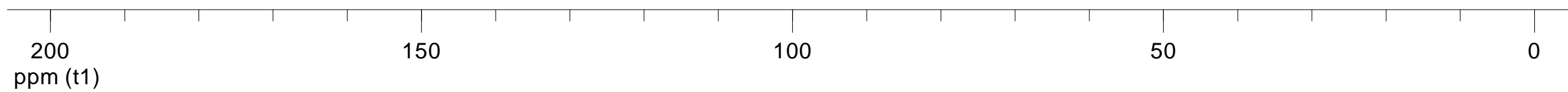




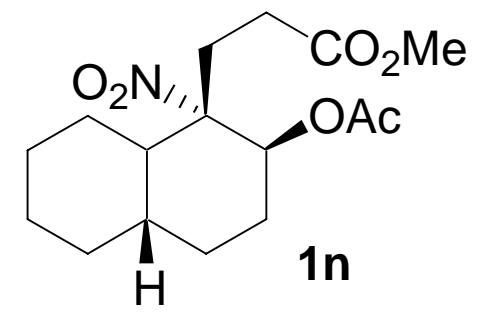

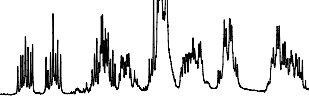

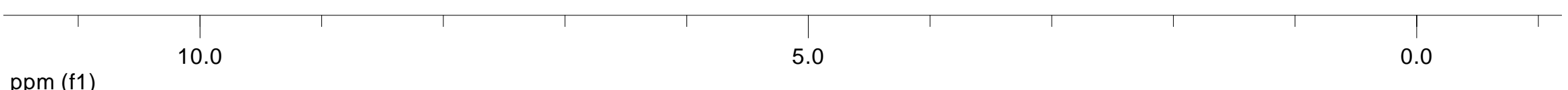

SI 44 

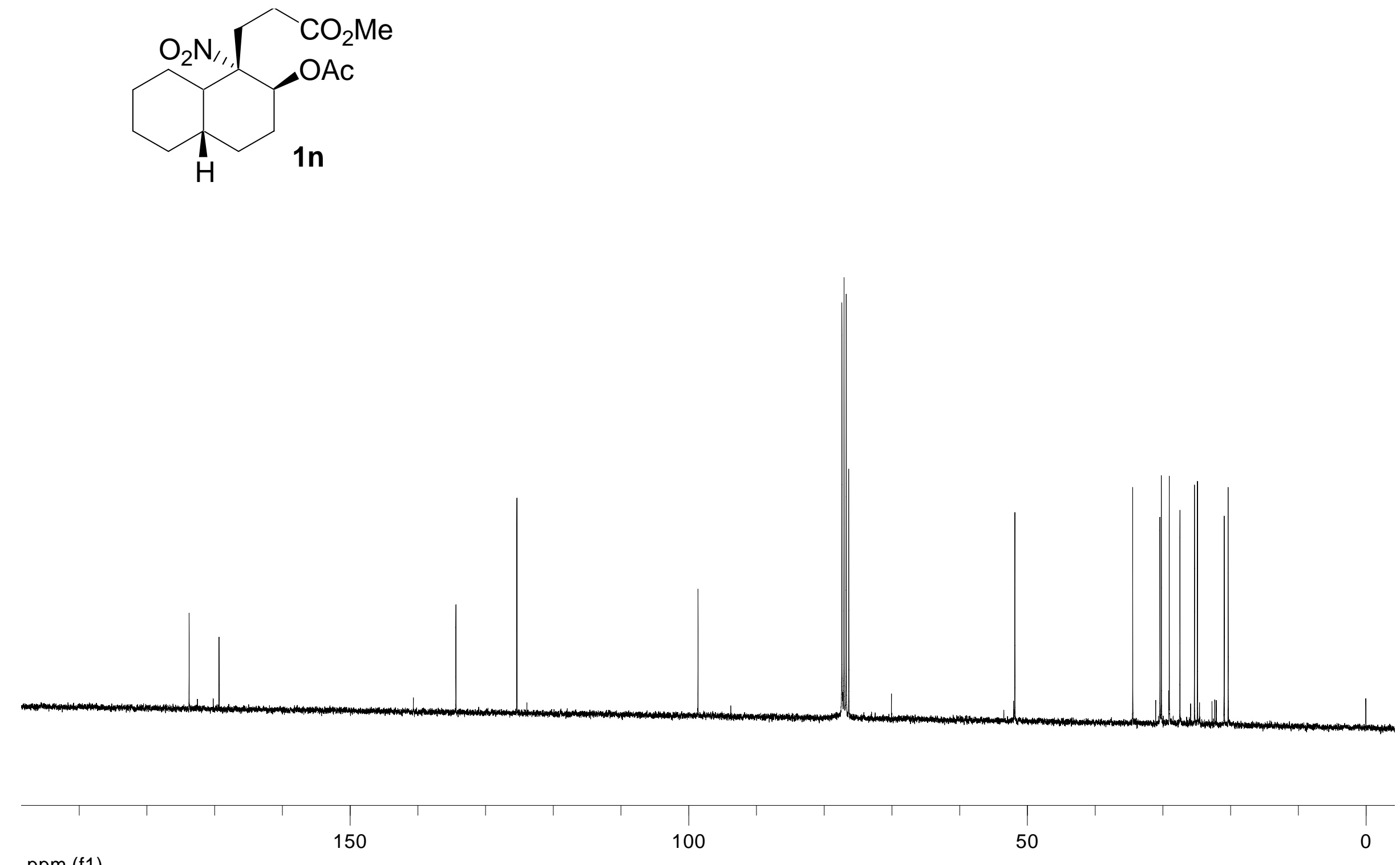

ppm (f1) 

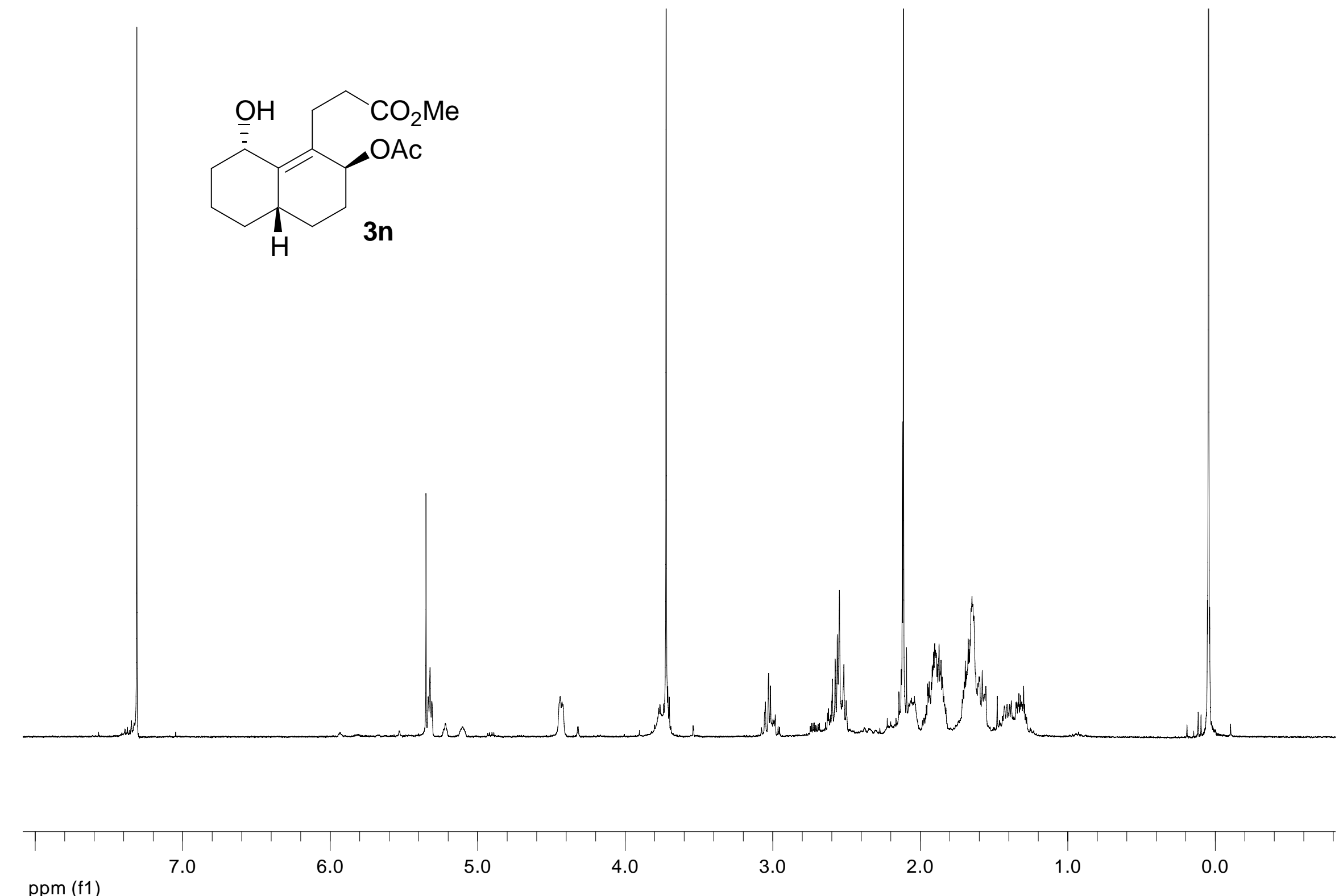

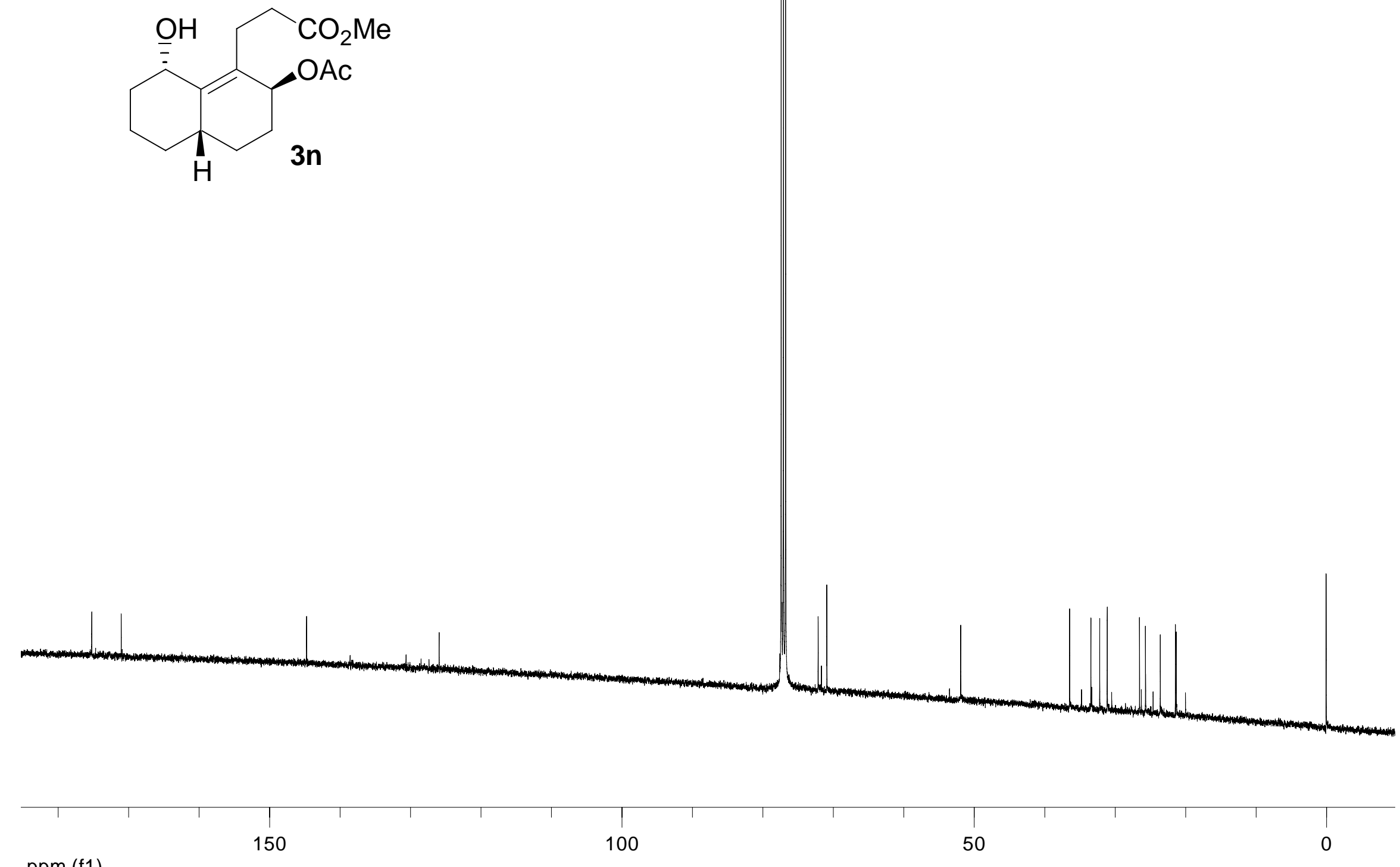

ppm (f1) 